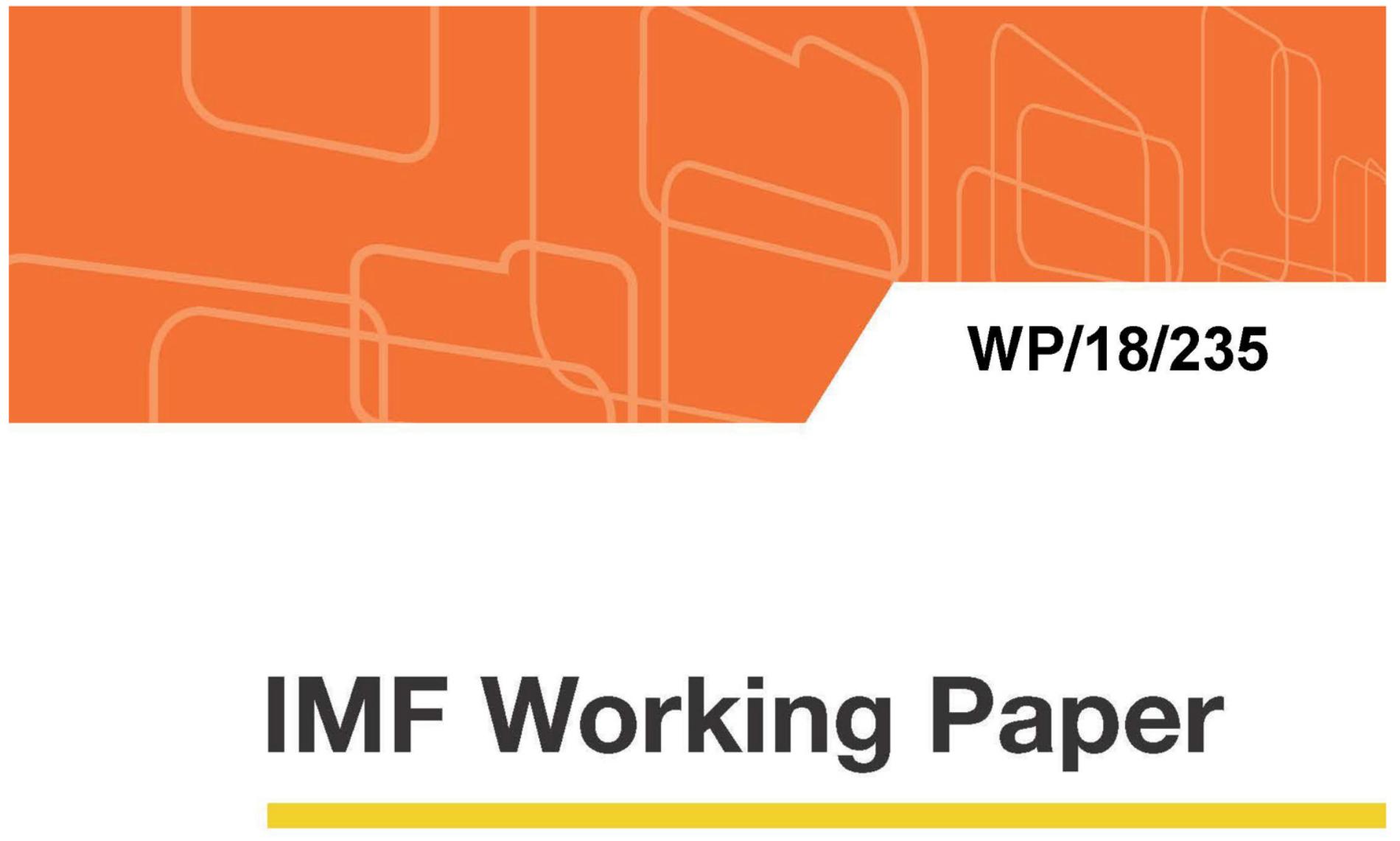

\title{
Monetary and Macroprudential Policy Coordination Among Multiple Equilibria
}

by Itai Agur

IMF Working Papers describe research in progress by the author(s) and are published to elicit comments and to encourage debate. The views expressed in IMF Working Papers are those of the author(s) and do not necessarily represent the views of the IMF, its Executive Board, or IMF management.

$$
\text { I N T E R N A T I O N A L M O N E T A R Y F U N D }
$$




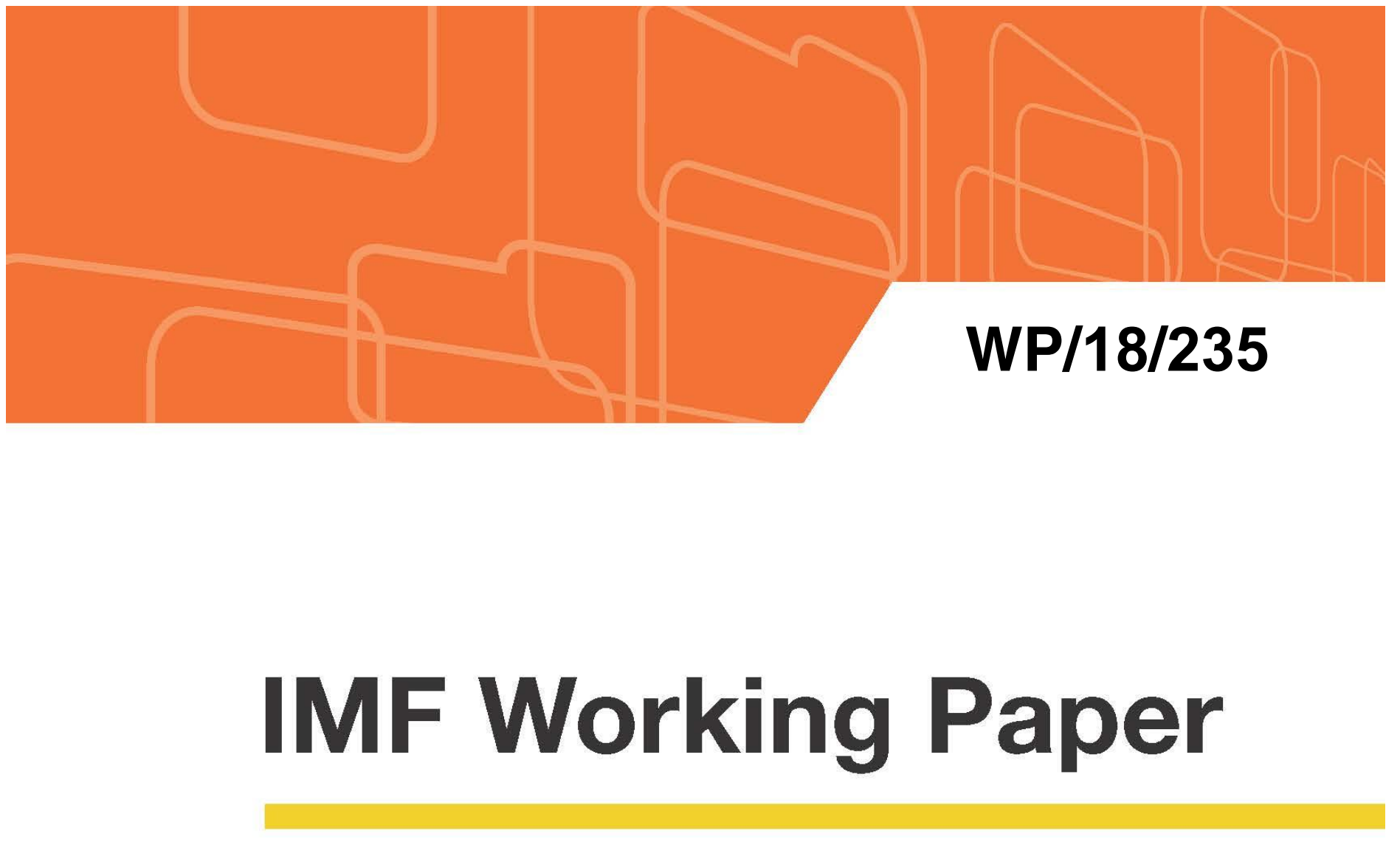

\section{Monetary and Macroprudential Policy Coordination Among Multiple Equilibria}

by Itai Agur

IMF Working Papers describe research in progress by the author(s) and are published to elicit comments and to encourage debate. The views expressed in IMF Working Papers are those of the author(s) and do not necessarily represent the views of the IMF, its Executive Board, or IMF management.

$$
\text { I N T E R N A T I O N A L M O N E T A R Y F U N D }
$$




\title{
IMF Working Paper
}

Research Department

Monetary and Macroprudential Policy Coordination Among Multiple Equilibria ${ }^{1}$

Prepared by Itai Agur

Authorized for distribution by Maria Soledad Martinez Peria

November 2018

\section{IMF Working Papers describe research in progress by the author(s) and are published to elicit comments and to encourage debate. The views expressed in IMF Working Papers are those of the author(s) and do not necessarily represent the views of the IMF, its Executive Board, or IMF management.}

\begin{abstract}
The notion of a tradeoff between output and financial stabilization is based on monetarymacroprudential models with unique equilibria. Using a game theory setup, this paper shows that multiple equilibria lead to qualitatively different results. Monetary and macroprudential authorities have tools that impose externalities on each other's objectives. One of the tools (macroprudential) is coarse, while the other (monetary policy) is unconstrained. We find that this asymmetry always leads to multiple equilibria, and show that under economically relevant conditions the authorities prefer different equilibria. Giving the unconstrained authority a weight on "helping" the constrained authority ("leaning against the wind") now has unexpected effects. The relation between this weight and the difficulty of coordinating is hump-shaped, and therefore a small degree of leaning worsens outcomes on both authorities' objectives.
\end{abstract}

JEL Classification Numbers: C72, E58, E61, G28

Keywords: Macroprudential Policy, Multiple objectives, Financial stability, Leaning. Author's E-Mail Address: iagur@imf.org

\footnotetext{
${ }^{1}$ I am grateful to Stephen Cecchetti, Liev Maribondo, Giovanni Dell'Ariccia, Maria Soledad Martinez Peria, Roland Meeks, Adina Popescu, and audiences at the IMF, the $29^{\text {th }}$ International Conference on Game Theory at Stony Brook, the 2018 RCEA Macro-Finance Conference in Warsaw and the XIII Annual Conference on Financial Stability and Banking of the Banco Central do Brasil for their comments.
} 


\section{Contents}

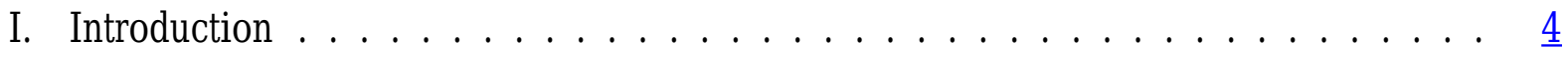

II. Game with unconstrained tools $\ldots \ldots \ldots \ldots \ldots \ldots$

III. Constrained tools . . . . . . . . . . . . . . . . . . . . . . . . . . . . . 10

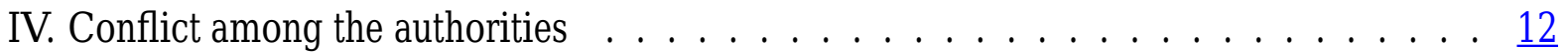

V. Coordination cost . . . . . . . . . . . . . . . . . . 13

A. The impact of leaning on coordination . . . . . . . . . . . 13

B. Non-equivalence of the authorities . . . . . . . . . . . . . . $\underline{15}$

VI. Social welfare implications … . . . . . . . . . . . . . . . . . 16

A. Leaning and social welfare . . . . . . . . . . . . . 16

B. First-best . . . . . . . . . . . . . . . . . . . 18

VII.Alternative game forms . . . . . . . . . . . . . . . . . . . . . . . . . 18

A. Stackelberg game . . . . . . . . . . . . . . . . . . . 18

B. Dynamic games . . . . . . . . . . . . . . . . . . . . 19

C. Merging the authorities . . . . . . . . . . . . . . 20

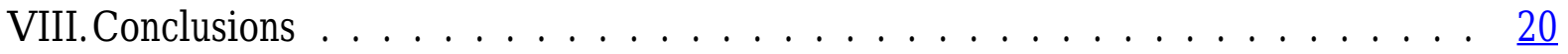

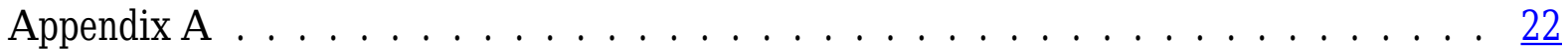

Appendix B . . . . . . . . . . . . . . . . . . . . . 27

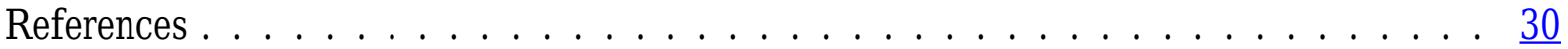

Figures

Figure 1. Output and financial gaps in numerical example . . . . . . . . . . . $\underline{9}$

Figure 2. Play towards the single Nash Equilibrium with unconstrained tools . . . . . $\quad \underline{9}$

Figure 3. How a constrained macroprudential tool gives rise to multiple Nash Equilibria . . . . . . . . . . . . . . . . . . . . . 11

Figure 4. Leaning and the loss functions of MA and REG . . . . . . . . . . . 14

Figure 5. The hump-shaped relation between leaning and coordination costs . . . . . . 15

Figure 6. Leaning backfires over full possible range . . . . . . . . . . . . . . . . . $\frac{17}{17}$

Figure 7. Leaning backfires over part of parameter range . . . . . . . . . . . . . . $\frac{17}{24}$

Figure 8. Third derivatives and conflicting equilibria. . . . . . . . . . . . . 24

Figure 9. Minimum coordination cost switches between authorities . . . . . . . $\underline{26}$

Figure 10. Hump-cum-plateau shaped relation . . . . . . . . . . . . . 26 


\section{INTRODUCTION}

In various countries monetary and macroprudential policies are assigned to different authorities (Nier et al., 2011). Although the central bank is usually at least part, and sometimes chair, of macroprudential policy committees, the need to coordinate across authorities features prominently in such structures, especially as part of the macroprudential toolkit often resides at the bank regulator (Agur and Sharma, 2013). Moreover, even when monetary and prudential policy are entirely conducted within the central bank, separating walls are often in place within the institution (Goodhart, 2000). Indeed, when monetary policy centers primarily on inflation targeting, the objectives of monetary and macroprudential policies imply a separation, regardless of whether those policies are conducted within the same institution.

The separation of monetary and macroprudential policies raises the specter of coordination problems. In recent years, a rapidly growing body of empirical literature has shown that the monetary policy rate significantly affects bank risk taking incentives (Maddaloni and Peydró, 2011; Jiménez et al., 2014; Dell'Ariccia, Laeven and Suarez, 2017). ${ }^{1}$ Monetary policy therefore imposes a direct externality on the financial stability objective of macroprudential policy. Similarly, macroprudential policy affects real economic activity and inflation (Kim and Mehrotra, 2018; Richter, Schularick and Shim, 2018). Such policy externalities point at a potential need for policy coordination.

Is it easier to work together when authorities are closer to wanting the same things? This question takes center stage in the literature on "leaning against the wind" (hereafter: leaning), which considers whether monetary policy should include a financial stability objective. Obviously, when objectives are truly identical, there can be no problem in coordinating. But even supporters of leaning, such as Borio and White (2004), Rajan (2006), Disyatat (2010), Schularick and Taylor (2012), Stein (2014), and Adrian and Liang (2018) do not suggest that monetary policy makers should care about financial stability to the same extent as prudential authorities. The relevant question is whether introducing some degree of leaning facilitates coordination.

To make headway in answering this question, we think it is essential to consider an environment of multiple equilibria. ${ }^{2}$ The literature on monetary-macroprudential interactions, discussed below, focuses on quantifying the welfare impact of moving between different unique equilibria (i.e., with and without leaning). But coordinating among multiple equilibria leads to qualitatively different tradeoffs, as we show.

\footnotetext{
${ }^{1}$ For further references, see Agur and Demertzis (2018). Theory literature has also microfounded the impact of monetary policy on bank risk, through: bank screening and monitoring incentives (Dell'Ariccia and Marquez, 2006; Dell'Ariccia, Laeven and Marquez, 2014); the skewness of bank returns (Valencia, 2014); information asymmetries (Loisel, Pommeret and Portier, 2012; Drees, Eckwert and Várdy, 2013; Dubecq, Mojon and Ragot, 2015); the incentives of bank loan officers (Acharya and Naqvi, 2012; Morris and Shin, 2016); nominal contracts between banks and creditors (Allen, Carletti and Gale, 2014); interbank liquidity and bank runs (Freixas, Martin and Skeie, 2011); and bailout moral hazard (Diamond and Rajan, 2012; Farhi and Tirole, 2012).

${ }^{2}$ For example, coordination problems with multiple equilibria have been investigated in the context of the literature on monetary policy communication (Morris and Shin, 2002).
} 
A game between an unconstrained and a constrained authority captures key elements of the monetary-macroprudential coordination problem. In particular, macroprudential policy grapples with a variety of constraints, meaning it faces hindrances in being perfectly geared towards its aim of containing systemic risk. Limitations of macroprudential policy include imprecise calibration, an uncertain degree of effectiveness, infrequent adjustment, arbitrage, and political economy problems (Lim et al., 2011; Galati and Moessner, 2013). Our modeling focuses on the imprecision aspect of macroprudential policy. For instance, a tightening of LTVs would generally proceed in large increments, such as from $90 \%$ to $80 \%$, which could be caused by the difficulty of calibrating the tool, political resistance to any change or to frequent adjustment (and therefore the need to proceed in jumps rather than small steps), or the challenges in communicating piecemeal macroprudential policy. Instead, monetary policy arguably has a greater degree of freedom, and we consider it here as a tool that is unencumbered.

A multiplicity of equilibria is inherent to the combination of quadratic loss functions and one constrained tool. In the game that we investigate, each authority aims to minimize a quadratic loss function with its own tool, given shocks and the play of the other authority. Authorities' tools impose externalities on each other's main objectives. If the tools were both entirely unconstrained, then a single Nash Equilibrium would emerge, which is socially optimal, as it matches the policy of a social planner minimizing both objectives with both tools. However, when one of the tools is constrained and cannot be precisely calibrated to meet its target, then there are always multiple Nash Equilibria.

In this context, we define leaning as introducing in the unconstrained authority's loss function a weight on "helping" the constrained authority, by jointly targeting its objective. Our key result is that the introduction of such a weight has surprising implications, and can lead to the opposite of its intent. There are several steps towards this result.

First, multiplicity of equilibria is a cause of conflict. There are different policy combinations (i.e., relatively loose monetary policy and tight macroprudential policy, and vice versa) that are sustainable as Nash Equilibria. But comparing equilibria, the outcomes for the two authorities can be very different. Therefore, they can prefer different equilibria. We derive sufficient conditions for which authorities indeed prefer different Nash Equilibria. The main sufficient condition is that the effectiveness of tools depends on their distance from neutral policy, which has an empirical grounding, as we discuss.

Second, the difficulty of coordinating among equilibria may rise rather than fall in the extent of leaning. We define the coordination cost as the minimum utility transfer that would convince the least resistant authority to coordinate on another equilibrium. The relation between this coordination cost and leaning is driven by two countervailing effects. On the one hand, when the unconstrained authority focuses primarily on its main objective, it keeps its loss function limited for any play of the constrained authority. This limits the cost that the unconstrained authority experiences in switching between equilibria. On the other hand, the more similar the aims of the authorities become (i.e., through leaning), the closer they come to preferring the same equilibrium. In the corners of no leaning or sufficiently large leaning, one equilibrium Pareto dominates another and coordination is costless. Instead, intermediate de- 
grees of leaning imply that the authorities still prefer different equilibria, but the payoff gaps (loss functions) between those equilibria are large. Thus, the relation between leaning and the coordination cost is hump-shaped.

Third, the "established tradeoff" - leaning limits financial imbalances at the cost of reduced output gap stabilization - is incomplete. Our game includes the established tradeoff when looking within Nash Equilibria. But when comparing among Nash Equilibria, the ability to coordinate matters. An equilibrium that the constrained authority dislikes, can be harder to circumvent when the unconstrained authority leans, because of the increased difficulty of coordinating. Hence, a leaning weight can perversely backfire, hurting the authority it was intended to help. Indeed, taking a uniform prior over multiple equilibria, we derive a clear-cut result: a small leaning weight always backfires, implying that a Pareto welfare loss ensues (worse performance on both objectives).

Galí (2014) also shows that leaning against the wind can backfire, although through a very different mechanism than ours. His setup centers on monetary policy only. Monetary policy's impact on rational asset bubbles is shown to be counterintuitive: a rational bubble can be spurred on by a rate hike, rather than counteracted. ${ }^{3}$

Calibrated models and empirical work instead take for granted that leaning improves financial stability and focus on the quantitative tradeoff: do the financial stability gains of leaning justify its cost from lost output gap stabilization? Econometric cost-benefit analyses are conducted by Svensson $(2014,2017 \mathrm{a}, \mathrm{b})$ and IMF (2015), who find that the benefits of leaning are small compared to its costs, whereas Filardo and Rungcharoenkitkul (2016) find large benefits to leaning.

Various DSGE models with financial frictions use calibrations to consider the welfare implications of monetary policy rules with and without leaning (Gerdrup et al., 2017; Loisel, 2014). Several such papers explicitly model a macroprudential regulator. In Collard et al. (2017) a complete separation of monetary and macroprudential objectives is optimal. Instead, in Bodenstein, Guerrieri and LaBriola (2016), Carrillo et al. (2017) and Van der Ghote (2018) financial stability objectives for monetary policy are quantitatively found to be welfare-improving. Moreover, in Angelini, Neri and Panetta (2014) a lack of cooperation between the authorities results in excessive volatility of both the policy rate and capital requirements. Policy in these papers is rules-based, which, as shown by Laureys and Meeks (2018), is only optimal when coordination fails: coordinated discretion-based monetary and macroprudential policy outperforms rules-based policy in their model.

De Paoli and Paustian (2017) and Cecchetti and Kohler (2014) bring in the dimension of a first-mover advantage. In De Paoli and Paustian (2017) having a macroprudential authority as first-mover welfare-dominates coordination. Instead, Cecchetti and Kohler (2014) find that a first-mover setup is inferior to coordination, and sometimes even to a noncooperative

\footnotetext{
${ }^{3}$ Brunnermeier and Koby (2017), Eggertsson, Juelsrud and Wold (2017) and Cavallino and Sandri (2018) also model monetary policy with non-standard effects, where below a threshold rate cuts become contractionary. Similarly, in Agur and Demertzis (2013) in response to a recession a leaning authority initially cuts rates deeper than an inflation targeter.
} 
simultaneous-moves game.

Compared to this literature, the key novelty of this paper's approach comes from the presence of multiple equilibria. We "trade in" the richness of a fully specified macroeconomic model in exchange for the richness of a game theoretical analysis allowing for a multiplicity of equilibria. The uniqueness of steady states is a prerequisite in DSGE model calibrations, one which we argue comes at a cost when analyzing the interactions among authorities. ${ }^{4}$ While we cannot quantify how important the exclusion of between-equilibrium effects is, highlighting that such effects exist is a first step towards their inclusion in policy debates.

A simple game theory analogy summarizes how our paper differs from the existing literature. The approach in the cited papers is akin to quantifying the difference between the unique outcome of a noncooperative Prisoner's Dilemma game and the optimal (coordinated) outcome for the prisoners. We think that the monetary-macroprudential coordination problem is instead more similar to the game below than to a Prisoner's Dilemma. The game below has two Nash equilibria, but the authorities disagree which of these is better. This is the type of game we get in our constrained tools model.

Example: payoffs of (Monetary,Macroprudential) authorities in relation to their play

\begin{tabular}{|l|l|l|}
\hline & Loose Macroprudential & Tight Macroprudential \\
\hline Loose Monetary Policy & Low, Low & High, Medium \\
Tight Monetary Policy & Medium, High & Low, Low \\
\hline
\end{tabular}

The next section presents the game with the benchmark case of unconstrained tools. Section III considers constrained tools and shows that these lead to multiple equilibria. Section IV identifies when this leads to conflict among the authorities. Section V defines the coordination cost and derives its relation to leaning. Section VI considers the welfare implications. Section VII discusses alternative game forms. Section VIII concludes.

\section{GAME WITH UNCONSTRAINED TOOLS}

We call the two authorities MA (monetary authority) and REG (macroprudential regulator). MA and REG focus on minimizing gaps, which represent cyclical states. In particular, MA's main objective is to minimize $y$, which we refer to as the output gap. ${ }^{5}$ The gap that REG cares about is denoted by $f$, which can be thought of as a "financial gap", derived from a "financial cycle", like the output gap relates to the business cycle (Borio, 2014).

The monetary policy rate is $r$, and the neutral rate is defined as $r=0$. Hence, a negative $r$ implies a rate cut relative to the neutral rate, and a positive $r$ is a tightening relative to the neutral rate. We apply a similar formulation to $m$, the tool of REG, which is aimed at limiting

\footnotetext{
${ }^{4}$ For more on the perils of ignoring multiple equilibria in macroeconomic modeling, see Blake and Kirsanova (2012).

${ }^{5}$ Absent supply shocks, output gap stabilization implies inflation stabilization (Blanchard and Galí, 2007).
} 
deviations in the financial cycle. We let $m=0$ represent the neutral stance, where positive (negative) $m$ stands for tight (loose) macroprudential policy. The focus here is therefore on containing the cyclical aspect of financial imbalances, as opposed to structural aspects: i.e., a countercyclical capital requirement rather than the base level of capital requirements, or a time-varying LTV rather than structural housing market policies.

Business and financial cycles are subject to shocks: $\varepsilon_{y}$ and $\varepsilon_{f}$. These shocks represent the values that, respectively, $y$ and $f$ would take, if policies are neutral $(r=0$ and $m=0)$.

The output gap is given by

$$
y\left(\begin{array}{c}
\left.\varepsilon_{y}, \underset{+}{m}, \underset{-}{r}, \underset{+}{f(\bullet)}\right) \\
+
\end{array}\right.
$$

while the financial gap is

$$
f\left(\begin{array}{c}
\varepsilon_{f}, \underset{+}{m}, \underset{+}{r}, \underset{+}{y}(\bullet) \\
+
\end{array}\right)
$$

Here we allow real and financial cycles to be interlinked ( $y$ and $f$ affect each other positively), but the correlation is less than one. Hence, $\frac{\partial y}{\partial f}<1$ and $\frac{\partial f}{\partial y}<1$. Given $\frac{\partial y}{\partial f}<1$ and $\frac{\partial f}{\partial y}<1$, terms can be replaced such that the above expressions can be written to

$$
\begin{aligned}
& Y\left(\begin{array}{c}
\varepsilon_{y}, \varepsilon_{f}, m_{-}, r \\
++-_{-}
\end{array}\right) \\
& F\left(\begin{array}{c}
\varepsilon_{f}, \varepsilon_{y}, m, r \\
++_{-}
\end{array}\right)
\end{aligned}
$$

where from $\frac{\partial y}{\partial f}<1$ and $\frac{\partial f}{\partial y}<1$ we also have that $\frac{\partial Y}{\partial \varepsilon_{y}}>\frac{\partial Y}{\partial \varepsilon_{f}}$ and $\frac{\partial F}{\partial \varepsilon_{f}}>\frac{\partial F}{\partial \varepsilon_{y}}$.

We write the optimization problems of, respectively, MA and REG as

$$
\begin{aligned}
& \min _{r}\left\{\lambda Y^{2}+(1-\lambda) F^{2}\right\} \\
& \min _{m}\left\{\omega F^{2}+(1-\omega) Y^{2}\right\}
\end{aligned}
$$

where we let $\lambda \in\left(\frac{1}{2}, 1\right]$ and $\omega \in\left(\frac{1}{2}, 1\right]$, as well as $\left|\frac{\partial Y}{\partial r}\right|>\left|\frac{\partial Y}{\partial m}\right|$ and $\left|\frac{\partial F}{\partial m}\right|>\left|\frac{\partial F}{\partial r}\right|$ : each authority has a dominant objective, and its tool has the dominant impact on that objective. Here, $\lambda=1$ implies that MA focuses only $Y$, whereas $\lambda<1$ implies leaning: MA weighs the financial gap as part of its mandate. To keep the initial setup general, we also allow for REG to have a weight on $Y$ in (6), although this will turn out to be of little relevance in the analysis ( $\omega$ could be set to 1 , without losing the main tradeoffs).

As a benchmark case, we first let both tools be unconstrained: $r$ and $m$ can be set to any value by the authorities. We let $r, m \in \mathbb{R}$. Denote the optimal responses by $r^{*}(m)$ and $m^{*}(r)$. Call 
Figure 1: Output and financial gaps in numerical example

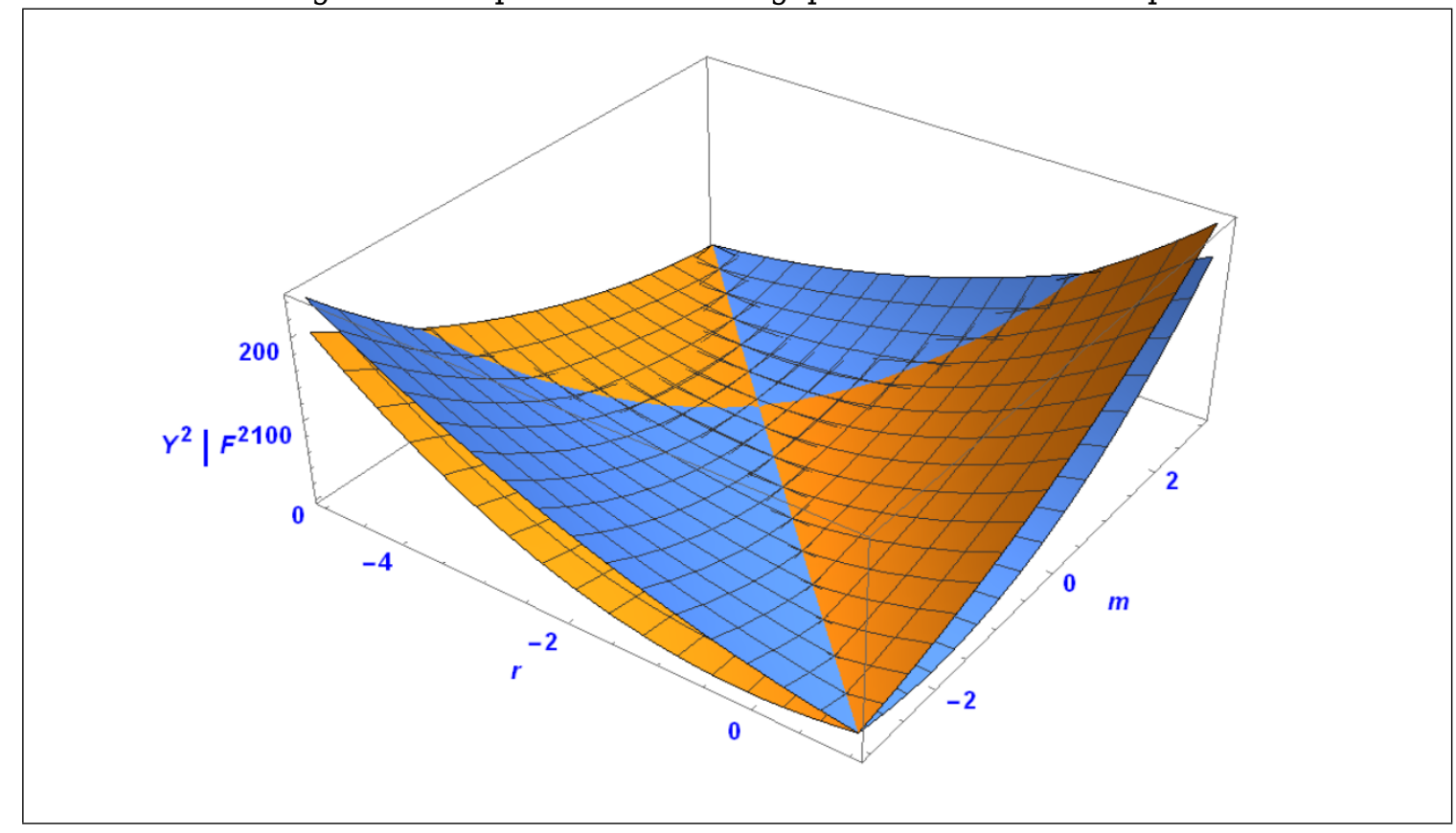

Figure 2: Play towards the single Nash Equilibrium with unconstrained tools

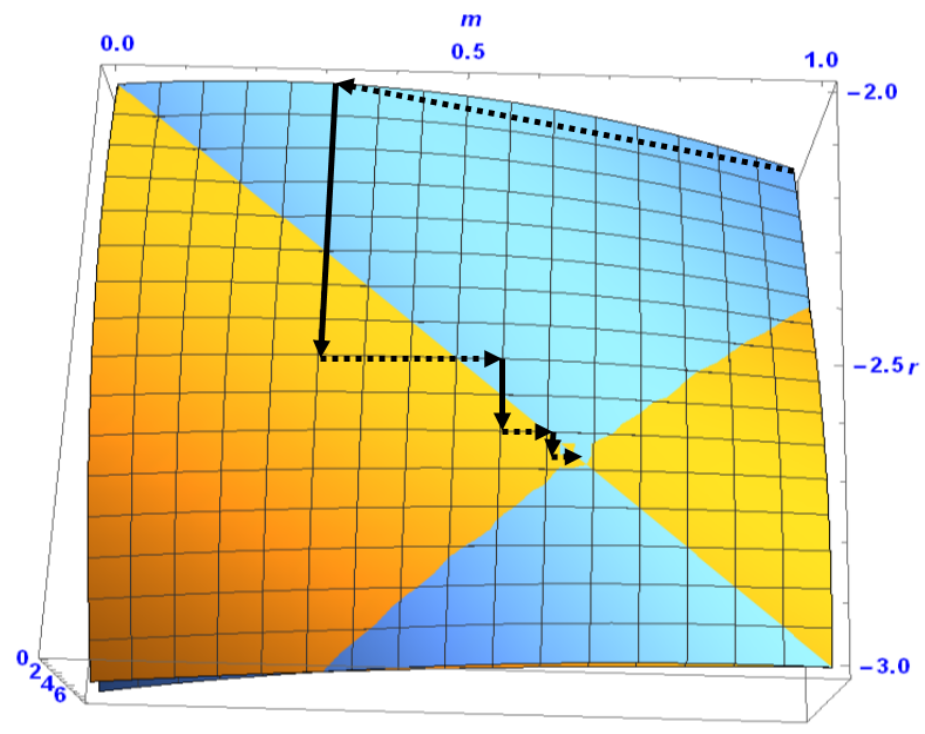


the socially optimal policy setting (i.e., what a single authority with two tools would implement) $\widehat{r}$ and $\widehat{m}$. Note that $r, m \in \mathbb{R} \Rightarrow \exists(r, m): Y^{2}=0 \wedge F^{2}=0$, as there are two unconstrained tools for two targets. That is, there exists a combination $(\widehat{r}, \widehat{m})$ which is unambiguously the social optimum (without a need to define the welfare function, given that both the output and financial gaps are completely closed). A social planner with unconstrained tools would always implement $(\widehat{r}, \widehat{m})$. But can the noncooperative Nash Equilibrium replicate this first-best outcome?

Proposition 1 establishes the relation between $(\widehat{r}, \widehat{m})$ and the Nash game with unconstrained tools. It shows that the unique Nash Equilibrium is always socially optimal.

Figures 1 and 2 graph a numerical example, derived from for an analytically solved specificform that is described in Appendix B. Figure 1 depicts both $Y^{2}$ and $F^{2}$ relative to $r$ and $m$. The blue plane is $F^{2}$ and the orange plane is $Y^{2}$. In regions where $F^{2}$ is greater than $Y^{2}$ the blue plane is higher, and vice versa. Here one can gauge that there is one crossing point, where $Y^{2}=F^{2}=0$. That crossing point is $(r, m)=(-2.67,0.67)$ in this example. Figure 2 pivots Figure 1 upside down (looking in from "below"), and zooms in on the Nash Equilibrium. Figure 2 shows how, starting from a given point outside of the Nash Equilibrium (here, $(r, m)=(-2,1))$ play would always progress towards the single, socially optimal Nash Equilibrium (REG's play is represented by the is dashed arrows, and MA's play is represented by the unbroken arrows).

Proposition 1 With unconstrained tools, the simultaneous moves game always has a single Nash Equilibrium. That Nash Equilibrium attains the social optimum, as $Y^{2}=0$ and $F^{2}=0$.

\section{Proof. In Appendix A.}

The reason that an unconstrained noncooperative game matches a social planner's outcome in our setting, is that authorities share the same global loss minimizing point. Regardless of the weights assigned to $Y^{2}$ and $F^{2}$ in (5) and (6), both MA and REG achieve minimal loss at the social optimum, and there is no other point where they both achieve this minimal loss. For an individual authority there can be other loss minimizing points (in particular, if either $\lambda=1$ or $\omega=1$ ), but at all points except the social optimum, the other authority would move. The authorities incentives "converge", as opposed to, say, a Prisoner's Dilemma, where individual incentives always "diverge" from the (prisoners') social optimum. The fact that there are externalities in our game changes nothing about these incentives, because each authority still has the dominant effect on its own main objective $\left(\left|\frac{\partial Y}{\partial r}\right|>\left|\frac{\partial Y}{\partial m}\right|\right.$ and $\left.\left|\frac{\partial F}{\partial m}\right|>\left|\frac{\partial F}{\partial r}\right|\right)$, and therefore the externalities can only "lengthen" the convergence path observed in Figure 2, but not undo it.

\section{Constrained tools}

We now consider $m \in \mathbb{Z}$. This is the simplest type of constraint to consider in our setting, namely a constraint on the precision of the macroprudential tool. That is, $m$ is a coarse tool, 
which can only be approximately calibrated, as represented by a restriction to the space of integers $(\mathbb{Z})$.

The optimization problem of MA is still as in (5). However, the optimization problem of REG now becomes

$$
\min _{m=\ldots-2,-1,0,1,2, \ldots}\left\{\omega F^{2}+(1-\omega) Y^{2}\right\}
$$

Proposition 2 The simultaneous moves game described by (5) and (7) always gives rise to multiple Nash Equilibria.

Proof. In Appendix A.

Figure 3: How a constrained macroprudential tool gives rise to multiple Nash Equilibria
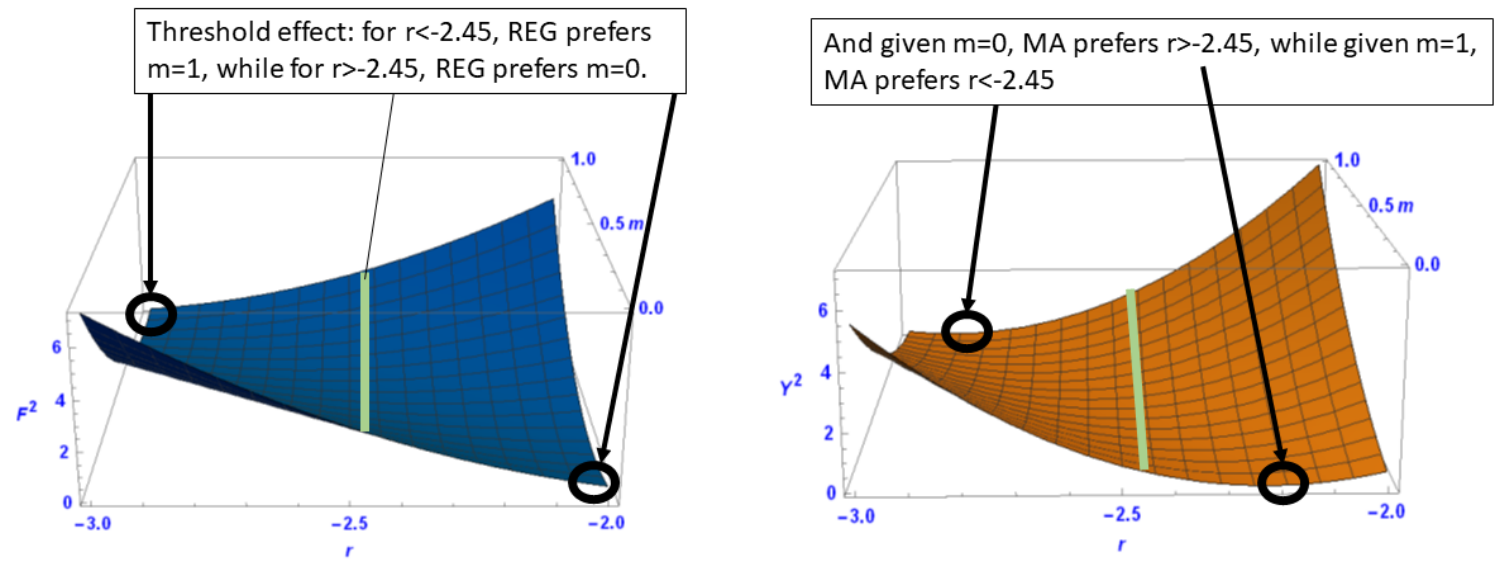

Figure 3 provides a representation of the emergence of multiple Nash Equilibria with constrained tools, derived from the quantified example in Appendix B. In that example, the optimal policy of REG takes a simple threshold form: set tight policy $(m=1)$ whenever $r<$ -2.45 and set neutral policy $(m=0)$ when $r>-2.45$. Moreover, as shown in Figure 3, if $m=1$ then MA's optimal policy is to set $r^{*}<-2.45$, while if $m=0$ then $r^{*}>-2.45$. That is, both points are sustainable as Nash Equilibria: combinations of relatively looser monetary policy and tighter macroprudential policy, and vice versa, are mutually reinforcing, making for optimal play for each authority given the play of the other. 


\section{CONFLICT AMONG ThE AUTHORITIES}

Multiplicity of equilibria does not necessarily imply a conflict among authorities. If both authorities prefer the same equilibrium (or one is indifferent and the other has a strict preference) then coordination is easy: cheap talk can eliminate Pareto dominated equilibria. Therefore, it is important to understand if and when authorities have genuinely conflicting preferences, and face a real problem in coordinating among the two equilibria. We now refer to two equilibria, because we have introduced the notion that Pareto dominated equilibria are eliminated. With two authorities, there can be at most two equilibria that are not Pareto dominated.

To facilitate the comparison of equilibria, we need to introduce some notation. Let $Y_{1}$ and $Y_{2}$ denote the value of $Y$ in equilibrium 1 and 2, respectively, and similarly for $F_{1}$ and $F_{2}$. What the authorities care about, then, is the squared values in the equilibria, denoted by $\left(Y_{1}^{2}, F_{1}^{2}\right)$ in equilibrium 1 and $\left(Y_{2}^{2}, F_{2}^{2}\right)$ in equilibrium 2. When either $Y_{1}^{2}>Y_{2}^{2} \wedge F_{1}^{2}<F_{2}^{2}$ or $Y_{2}^{2}>$ $Y_{1}^{2} \wedge F_{2}^{2}<F_{1}^{2}$, there is the potential for conflict among authorities, as the output gap is smaller in one equilibrium, and the financial gap is smaller in the other equilibrium.

However, to identify a precise set of conditions that imply conflict, we need to narrow down the set of constraints on the macroprudential tool. Essentially, REG's optimization problem in (7), with $m \in \mathbb{Z}$, is too coarse to derive the sufficient conditions for conflict. For example, consider some specific-form (like the example in Appendix B) that yields a solution for $\widehat{m}$, which happens to be 0.9 . Then, even though both $m=0$ and $m=1$ are Nash Equilibria, it is quite likely that both authorities will prefer $m=1$, as it happens to be much closer to the social optimum. The constraint $m \in \mathbb{Z}$ is useful as a simple, initial approximation for constrained policy, but when analyzing the potential for conflicting preferences, the most relevant case is that of a tool that is symmetrically constrained around the social optimum. In the example of $\widehat{m}=0.9$, a symmetric constraint could be choosing between $m=0.8$ and $m=1$.

We let $\mathrm{m}^{-}$and $\mathrm{m}^{+}$, respectively, denote the feasible values of $m$ below and above $\widehat{m}$, and let $m^{+}-\widehat{m}=\widehat{m}-m^{-}$, implying the constraints are symmetric. Then, REG's optimization problem is written to

$$
\min _{m=\left\{m^{-}, m^{+}\right\}}\left\{\omega F^{2}+(1-\omega) Y^{2}\right\}
$$

Using (8), we are able to show that multiplicity of equilibria always leads to a conflict of preferences under the following set of three (sufficient but not necessary) conditions:

1. Linear separability of shocks: $\varepsilon_{y}$ and $\varepsilon_{f}$ are intercept shocks, which is standard in most macroeconomic models.

2. A marginal leaning weight: we focus on $\lambda=1-v$ with $v \rightarrow 0^{+}$, where $v$ can be seen as the introduction of a marginal weight on financial stability objectives for MA. Moreover, we let $\omega=1$. This makes it possible to conduct a qualitative analysis without the need to specify a welfare function, because $Y_{1}^{2}>Y_{2}^{2} \wedge F_{1}^{2}<F_{2}^{2}$ or $Y_{2}^{2}>$ $Y_{1}^{2} \wedge F_{2}^{2}<F_{1}^{2}$ then implies conflicting preferences among the authorities. As discussed in Section V.B, there is no loss of generality from setting $\omega=1$. 
3. Nonlinearity between targets and tools: the response of output and financial gaps to, respectively, $r$ and $m$, is not perfectly linear. That is, $\frac{\partial^{2} Y\left(\varepsilon_{y}, \varepsilon_{f}, m, r\right)}{\partial r^{2}}$ and $\frac{\partial^{2} F\left(\varepsilon_{y}, \varepsilon_{f}, m, r\right)}{\partial m^{2}}$ are either positive or negative. In reality, we would expect these second derivatives to be positive: the impact of a marginal change in a tool weakens in its distance from neutral policy. For example, a policy rate cut can have different implications depending on the level from which the rate is cut. Several studies have found empirically that as interest rates get lower, their impact on bank lending and on the real economy weakens (Eggertsson, Juelsrud and Wold, 2017; Heider, Saidi and Schepens, 2017; Hong and Kandrac, 2018). Similarly, loosening macroprudential policy likely has a declining impact, as prudential limits cease to bind beyond a certain point, while the impact of tightening macroprudential policy can also weaken, and even reverse, if it comes to the point where risk taking incentives are perversely spurred (Perotti, Ratnovski and Vlahu, 2011), or if circumvention increases as a result of excessive tightening.

Proposition 3 Under the three properties outlined above, MA and REG prefer different Nash Equilibria.

Proof. In Appendix A.

\section{Coordination Cost}

The previous section identified sufficient conditions for conflicting preferences among the authorities. The next step is to define an expression that summarizes the depth of conflict. How far apart are authorities? How difficult would it be to sit together and coordinate on a different outcome? One could imagine that if one authority is only slightly better off under an equilibrium that makes the other a lot worse off, a small degree of altruism (or public pressure) could suffice to make the minimally affected authority move. But the more that minimally affected authority has to give up in terms of its objectives, the less inclined it will be to agree to a coordinated outcome.

We identify the extent of disagreement between MA and REG with this coordination cost expression

$$
C=\min \left\{\mid\left[\begin{array}{l}
\left.\mid \lambda Y_{1}^{2}+(1-\lambda) F_{1}^{2}\right]-\left[\lambda Y_{2}^{2}+(1-\lambda) F_{2}^{2}\right]|,| \\
\left|\left[\omega F_{1}^{2}+(1-\omega) Y_{1}^{2}\right]-\left[\omega F_{2}^{2}+(1-\omega) Y_{2}^{2}\right]\right|
\end{array}\right\}\right.
$$

One can see (9) as a means to quantify what one authority would have to minimally "offer" the other in order to move. If there were some means to transfer utility between authorities, then the coordination cost is the minimum utility transfer required.

\section{A. The impact of leaning on coordination}

We can now analyze how the coordination cost is impacted by the extent of leaning. That is, how does $C$ vary with $\lambda$ ? Proposition 4 shows that the coordination cost is lowest in the cor- 
ners where there is no leaning at all, or where authorities are sufficiently similar. In between, coordination is harder. In particular, the relationship between the extent of leaning and the coordination cost is hump shaped. This is summarized in Figures 4 and 5.

Figure 4: Leaning and the loss functions of MA and REG

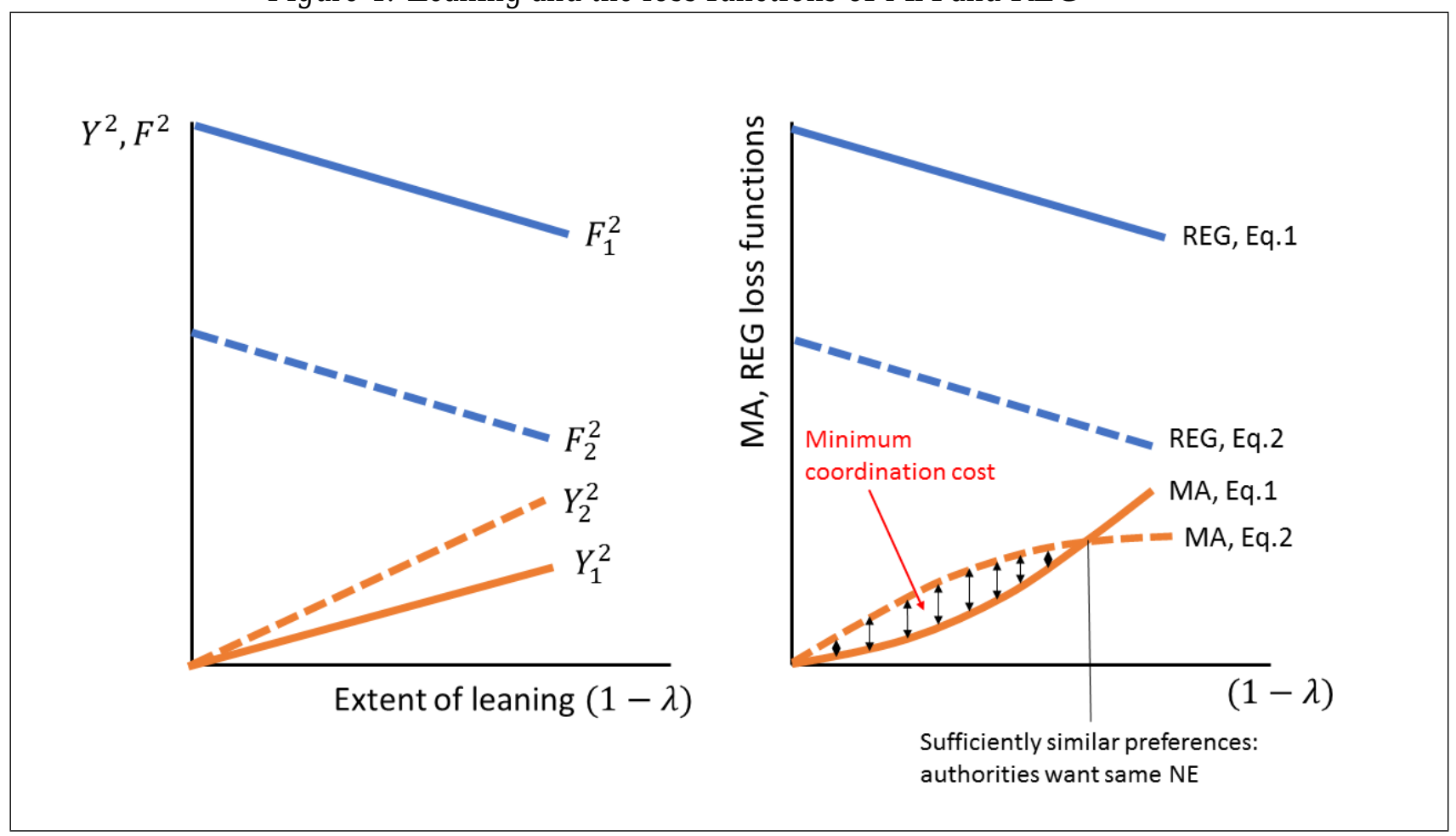

The left pane of Figure 4 represents the conflict between real and financial objectives, as in Proposition 3. At $\lambda=1$ (no leaning), MA always closes the output gap. But for any $\lambda<$ 1 , the output gap is larger in one equilibrium (NE2), while the financial gap is larger in the other (NE1). As long as MA's weight on the output gap dominates, it will prefer NE1. But at some point, when MA's weight on financial objectives becomes large enough, it will switch to preferring NE2. This is represented in the right pane of Figure 4.

This implies a hump-shaped relation between leaning and coordination cost, shown in Figure 5 and proven in Proposition 4. Starting from no leaning, the introduction of a small weight on leaning always increases the coordination cost. The reason is that for a small weight, the MA certainly still prefers the equilibrium with the lower output gap (here, NE1). Leaning reduces the financial gap and increases the output gap in each equilibrium. Because output gaps widen as MA leans more, the coordination cost first rises in leaning. However, MA's preferences also move closer to those of REG. Eventually, the convergence of preferences "overtakes" the divergence of equilibrium outcomes, and coordination cost declines in leaning, until it reaches zero again. We call the point at which authorities' preferences are sufficiently similar that they prefer the same equilibrium, $\lambda=\widehat{\lambda}$.

In sum, in terms of coordination, the problematic cases occur when authorities are different enough from each other that they prefer different equilibria, but not so different from each 
Figure 5: The hump-shaped relation between leaning and coordination costs

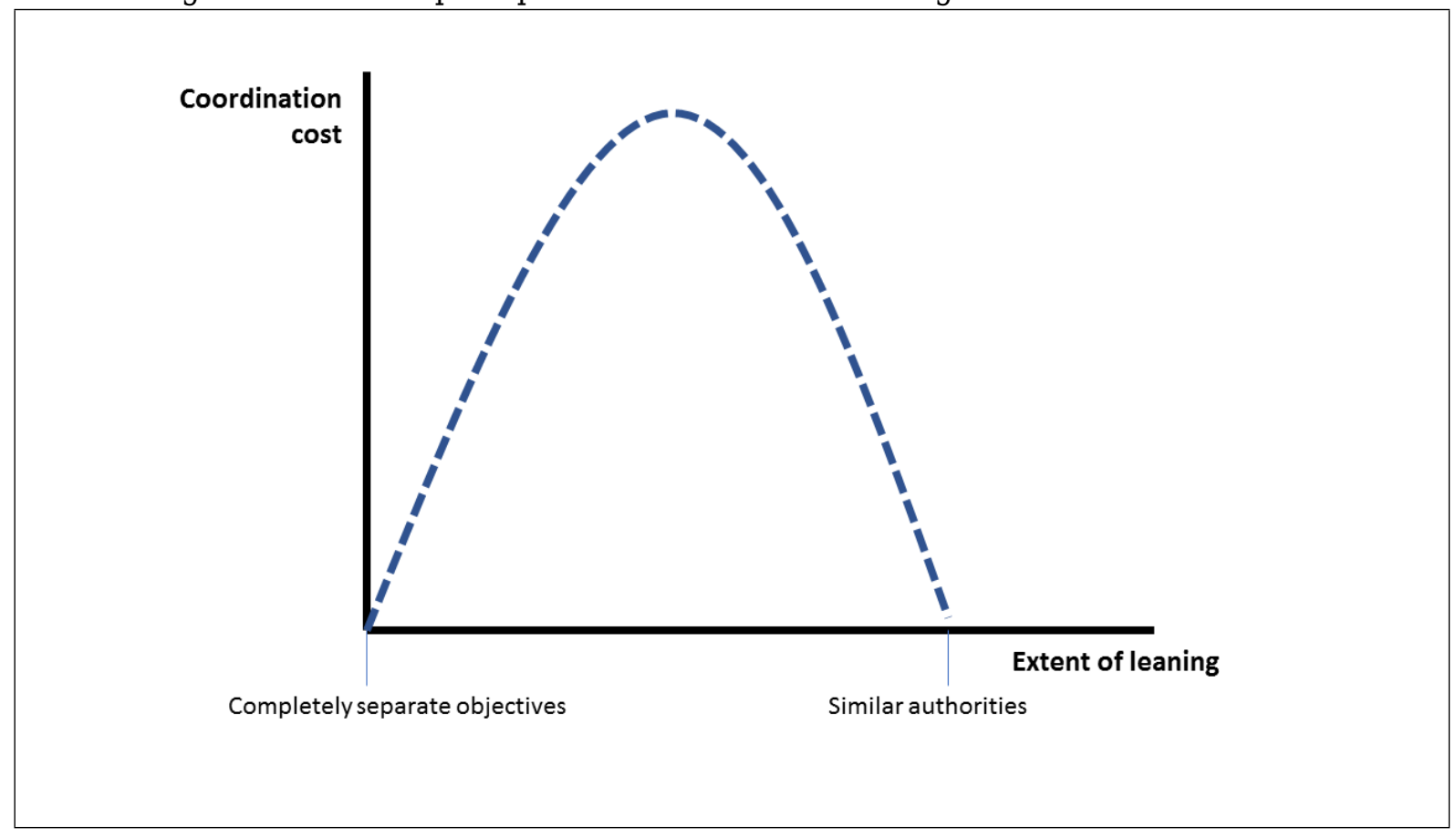

other that coordination costs are small, because one authority is always close to achieving its target. This happens when the leaning parameter is in the intermediate range.

Proposition 4 For the same set of conditions outlined for Proposition 3, the coordination cost $C$ is hump-shaped in the extent of leaning, $(1-\lambda)$, with $C=0$ at the corners of no leaning $(\lambda=1)$ and sufficiently similar preferences $(\lambda=\widehat{\lambda})$.

Proof. In Appendix A.

\section{B. Non-equivalence of the authorities}

Our analysis has centered on $\lambda$, and the relation between leaning and coordination problems. But would a similar comparison apply to $\omega$, whereby a pure regulatory focus on financial imbalances $(\omega=1)$ eliminates coordination problems? That is not the case, because of the asymmetry of tools, $m$ and $r$. The interest rate is modeled as a precision tool, whereas macroprudential policy is coarse. But such an asymmetry between the tools implies that Proposition 4 's result on $\lambda$ has no equivalent for $\omega$. That is, $\omega \rightarrow 1 \nRightarrow F^{2}=0$, and therefore there is no general-form, qualitative statement on the relation between $C$ and $\omega$. 


\section{SOCIAL WELFARE IMPLICATIONS}

Without defining a welfare function, we can nonetheless discuss the impact of leaning on the most conservative definition of welfare changes: Pareto improvements. Here, a Pareto welfare improvement comes about whenever both $Y^{2}$ and $F^{2}$ are lower for a change in $\lambda$. We qualitatively compare $\lambda=1$ (inflation targeting) and $\lambda<1$ (leaning). It is obvious that $Y^{2}$ is always lowest at $\lambda=1$ (since $r$ is then always adjusted to effectuate $Y^{2}=0$ ). Hence, the welfare comparison can center on $F^{2}$ : if $\lambda<1$ implies a higher value of $F^{2}$ than does $\lambda=1$, then $\lambda<1$ unambiguously (Pareto) worsens social welfare.

\section{A. Leaning and social welfare}

The tradeoff here is as follows. On the one hand, leaning lowers $F^{2}$ within each Nash Equilibrium. That is, within equilibria, the tradeoff between leaning and inflation targeting takes the "traditional" form, whereby leaning implies a loss on output gap stabilization, but gains on financial stabilization. Formally, $\frac{\partial F_{1}^{2}}{\partial \lambda}>0$ and $\frac{\partial F_{2}^{2}}{\partial \lambda}>0$, because for any given $m, r^{*}(m)$ attains a lower $F^{2}$ when $\lambda$ is smaller (by (5)). This is seen in Figure 4. On the other hand, leaning can make it harder to coordinate among Nash Equilibria, and therefore increases the likelihood of landing on the worse of $F_{1}^{2}, F_{2}^{2}$. This statement can be made more precise by assuming a uniform prior over Nash Equilibria: absent successful coordination, each equilibrium is equally likely to occur. This allows us to speak of $E\left[F^{2}\right]$. If authorities fail to coordinate, then

$$
E\left[F^{2}\right]=\frac{F_{1}^{2}+F_{2}^{2}}{2}
$$

Since the aim of leaning is to reduce financial imbalances, we refer to a situation wherein $E\left[F^{2}\right]$ rises in the extent of leaning as "backfiring leaning". That is:

$$
\frac{\Delta E\left[F^{2}\right]}{\Delta \lambda}<0
$$

which means that, starting from $\lambda=1$, and then introducing a weight on leaning (a reduction of $\lambda$ by $\Delta \lambda$ ) would increase $E\left[F^{2}\right]$. Backfiring leaning implies that leaning lowers social welfare in a Pareto sense, because it raises both output and financial gaps. This is seen in Figures 6 and 7.

Proposition 5 provides a benchmark result for backfiring leaning, when conflicting preferences cannot be overcome and only Pareto-dominated equilibria can be eliminated.

Proposition 5 If authorities fail to coordinate when $C>0$ (one authority needs to be made worse off to make the other better off), then there exists as $\lambda^{\prime} \in[\widehat{\lambda}, 1)$ such that a change from $\lambda=1$ to $\lambda \in\left(\lambda^{\prime}, 1\right)$ always Pareto worsens welfare $\left(\frac{\Delta E\left[F^{2}\right]}{\Delta \lambda}<0\right.$ and $\left.\frac{\Delta E\left[Y^{2}\right]}{\Delta \lambda}<0\right)$. 
Figure 6: Leaning backfires over full possible range

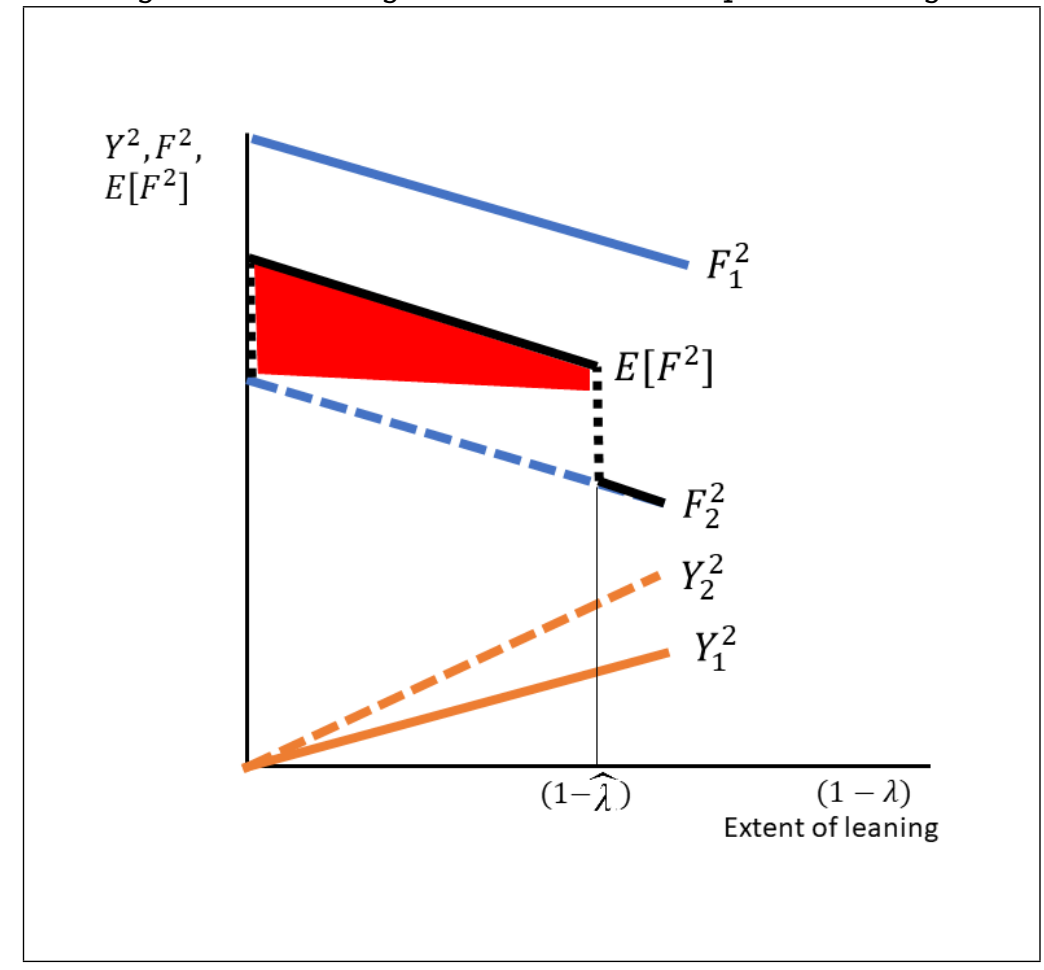

Figure 7: Leaning backfires over part of parameter range

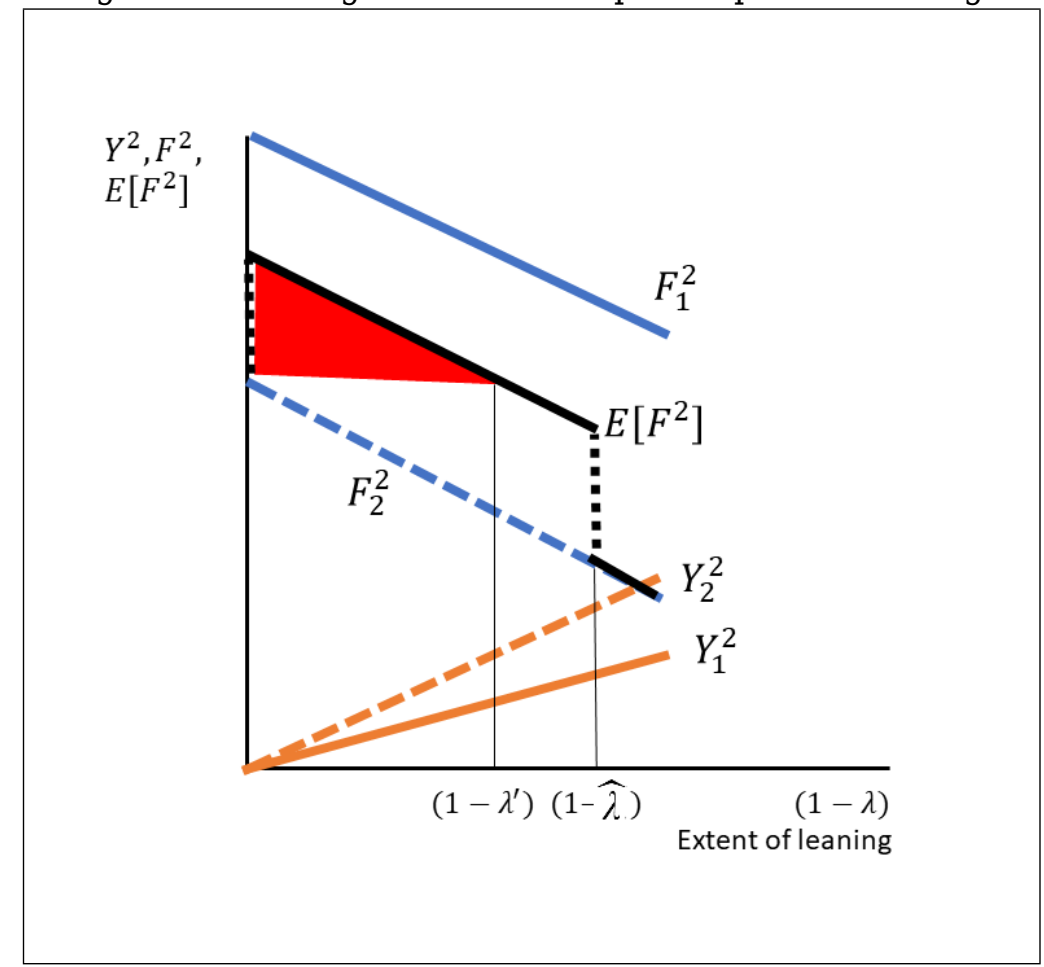

CInternational Monetary Fund. Not for Redistribution 


\section{Proof. In Appendix A.}

While we have derived this result using the assumption of a uniform prior, it is useful to note that a uniform prior is not a necessary condition. Indeed, from Figures 6 and 7 it is easy to see that, qualitatively, the result would go through for any prior that places weights strictly above $0 \%$ on each of $F_{1}^{2}$ and $F_{2}^{2}$.

\section{B. First-best}

Section II showed that under unconstrained tools the two separate authorities could replicate the social planner's solution. For the case of constrained tools, we have not considered the social planner's solution. That is because we have not gone down the path of specifying a welfare function. Under constrained tools and conflicting preferences, which equilibrium is better from a welfare perspective, the one preferred by MA or the one preferred by REG, cannot be answered without a welfare function. However, for present purposes, what matters is the knowledge that the two equilibria are different, and therefore, barring a knife-edge case, social welfare would always be higher in one of them. The inability to coordinate can impose costs, by bringing about the possibility that a lower welfare equilibrium wins out. For this, we need not quantify which equilibrium has the lower welfare.

\section{Alternative game forms}

This paper has focused on a one-shot simultaneous-moves games between two authorities, because this setting is both simple and leads to interesting tradeoffs. Extensions to first-mover, repeated games or a single authority optimizing two tools are feasible, but their outcomes would be quite straightforward here, as discussed below.

\section{A. Stackelberg game}

A first-mover setup automatically leads to coordination on the preferred equilibrium of the authority that is appointed as the Stackelberg leader. If MA is the first mover, then it sets the optimal $r$ taking into account how REG responds with $m$ at the next stage. Hence, it sets the $r$ that replicates its preferred Nash Equilibrium. Conversely, if REG is a first-mover, then it sets a value of $m$ so that MA's subsequent response leads to REG's preferred equilibrium.

While a fixed Stackelberg assignment resolves the multiplicity of equilibria, it does not resolve the underlying coordination problem. Either MA or REG's preferred equilibria may be socially optimal, and which of these is socially optimal can depend on parameters, i.e., it may be impossible to specify "in advance" which authority should be given the first-mover advantage. 
To see this, we can define a general welfare function, $W\left(Y^{2}, F^{2}\right)$, which is a (decreasing) function of output and financial gaps - we do not need to define the exact form here. However, we note from (3) and (4) and the discussion below these equations that $\frac{\partial Y}{\partial \varepsilon_{y}}>\frac{\partial Y}{\partial \varepsilon_{f}}>0$ and $\frac{\partial F}{\partial \varepsilon_{f}}>\frac{\partial F}{\partial \varepsilon_{y}}>0$. This means that shocks $\varepsilon_{y}$ and $\varepsilon_{f}$ affect output and financial gaps differently. Hence, there may be a set of shocks such that $Y^{2}$ is relatively large and $F^{2}$ small or zero, or vice versa. Depending on the shocks, welfare $W\left(Y^{2}, F^{2}\right)$ is better served by focusing on limiting the output or the financial gap, respectively. That is, which of the equilibria, $\left(Y_{1}^{2}, F_{1}^{2}\right)$ or $\left(Y_{2}^{2}, F_{2}^{2}\right)$, is better for welfare, can vary with shocks, $\varepsilon_{y}$ and $\varepsilon_{f}$.

In an economic environment where the financial gap is small, the policy combination of $(m, r)$ may not matter much for $F^{2}$ : the gap is squared, so small deviations around $F=0$ have little impact on welfare. If instead $Y^{2}$ differs strongly among policy combinations, then Stackelberg leadership for MA would raise welfare, ensuring that authorities settle on the equilibrium with lower $Y^{2}$. Instead, we can take a different set of shocks, $\varepsilon_{y}$ and $\varepsilon_{f}$, such that lowering $F^{2}$ is the key welfare consideration, and Stackelberg leadership for REG is ideal.

Which equilibrium is better for social welfare, would be time-varying, as economic conditions change. Therefore, the only way to always ensure play towards the welfare-dominant equilibrium, would be to have an overarching authority that reassigns the first-mover every period to ensure play towards the welfare-dominant equilibrium. However, that is not a realistic setup: a first-mover would normally be assigned by the creation of institutional frameworks that are not frequently altered.

\section{B. Dynamic games}

Dynamic games can sometimes allow for strategies, such as Tit-for-Tat retaliation, which help avert bad equilibria. However, when the game is one where each authority has a single preferred equilibrium, there may be little scope for such mechanisms to improve on outcomes. The authorities fundamentally disagree on which is the bad equilibrium that needs to be avoided, and this does not change with repetition, nor does the fact that either equilibrium can be better from a social planner's point of view.

It is possible that one authority would find itself in a stronger position in a dynamic game. For example, MA's tool could have considerably larger externalities on $F^{2}$ than REG's tool has on $Y^{2}$. If so, REG may be very sensitive to any threat made by MA. For instance, MA may play a strategy whereby it either gets the equilibrium it prefers, or sets $r$ at a level that is particularly damaging to REG's objective, in which case REG's best response could be to yield to MA. But while game repetition can affect which authority gets the "upper hand", potentially resolving the multiplicity of equilibria, this does not necessarily improve upon the coordination problem. As discussed in the Stackelberg game, welfare could go either way and, more importantly, which equilibrium is better for welfare can depend upon the underlying shocks. A dynamic game would either be a simple repetition of the one-shot game or, if more complicated strategies are played, it effectively becomes an assignment of a Stackelberg-like advantage to the authority that happens to be more influential. 


\section{Merging the authorities}

This paper started from the observation that, in practice, monetary and macroprudential policies are often conducted by separate authorities. Since the coordination problem emanates from this separation, a simple solution is to merge the authorities. If that single authority with two tools is made to optimize welfare, then it obviously becomes identical to a social planner in our setup. If the authority is given the preferences of either MA or REG only, then we are back at the point discussed in the Stackelberg case, as the outcome for welfare depends on the nature of the shocks.

In reality, there are other considerations concerning the merger of authorities that are unmodeled here, and which may be inherently difficult to model. For instance, when monetary and prudential policies are both conducted by the central bank, a financial crisis, if seen as due in part to insufficient prudential policy and oversight, can negatively affect the credibility of monetary policy too; or the threat of negative reputational effects from financial instability may induce the central bank to divert monetary policy - agency considerations that hint at a potential conflict of interests (Eijffinger, 2001).

\section{Conclusions}

The debate on whether monetary policy should engage in "leaning against the wind" is usually framed in terms of a cost-benefit analysis: is a leaning central bank's hampered ability to stabilize the output gap and inflation outweighed by its financial stability benefits? This paper takes a different angle. Rather than asking about relative costs and benefits within equilibria, it considers the tradeoffs involved in coordinating between equilibria. The core components of the model are quadratic loss functions, externalities from the use of tools, and the fact that one of the tools is constrained. The combination of these components implies multiple equilibria. Introducing one more component, namely the empirically relevant notion that the impact of tools gets weaker the farther they are from neutral, the authorities are found to prefer different equilibria. The disagreement between the authorities can be captured in an expression that measures the distance between their preferences over equilibria. In turn, that expression can be related to "leaning against wind", using comparative statics to the weight that the unconstrained authorities places on the objective of the constrained authority.

We find that the distance between authorities preferences over equilibria first rises in leaning and then falls. Along the path of making the unconstrained player more similar to the constrained player, the ability of the unconstrained player to meet its target is impeded, and this actually makes him more averse to switching equilibria. The unconstrained player becomes keener to stick to his preferred equilibrium, because switching involves a larger loss when he cannot solely use his tool to undo the damage of a switch. Only when the unconstrained player is so similar to the constrained player that he prefers the same equilibrium, does this coordination problem vanish.

Taken together, these effects imply that a small weight on leaning achieves the opposite of its 
intent. From the perspective of financial stability, such a weight has: a discrete disadvantage, by turning the unconstrained authority away from indifference between the equilibria towards a strict preference, giving birth to the coordination problem between equilibria; but only a marginal advantage, reducing financial instability within equilibria. A discrete cost always outweighs a marginal benefit at first.

To translate this result into a policy recommendation, a crucial open question is: how small is small? Over what range of leaning parameters does the hump-shape in Figure 5 take place? If, say, the entire hump-shape is contained within a $0-1 \%$ weight on financial stability in monetary policy optimization, then policy makers lose relatively little by ignoring this paper's between-equilibrium effects, and can seek guidance in the existing literature on quantifying within-equilibrium effects. But if, instead, the hump-shape ranges from, say, 0-20\% weight, then ignoring between-equilibrium effects can lead policy astray.

New modeling venues may be opening up that will eventually allow for a merger of this paper's analysis and calibrated macroeconomic models. In particular, Gertler, Kiyotaki and Prestipino (2017) develop a New Keynesian model with bank runs, and calibrate the probability of sunspots that trigger moves between run and no-run equilibria. In Gertler, Kiyotaki and Prestipino (2017) the multiplicity of equilibria is at the level of economic agents, not policy makers. That is, policy is made while taking into account the probability of different agent equilibria. In our framework, policy itself is the cause of multiplicity, and therefore the approach of Gertler, Kiyotaki and Prestipino (2017) would not be directly applicable: sunspots relate to agent expectations, not to policy maker preferences. Nonetheless, the gap between this paper's game theory approach and what is feasible to include in quantifiable models, may be narrowing. 


\section{Appendix A: Proofs}

Proof of Proposition 1. First, note that $Y^{2}=0 \wedge F^{2}=0$ is a Nash Equilibrium, because neither authority has an incentive to move at that point. Second, the uniqueness of the Nash Equilibrium follows from $\lambda \in\left(\frac{1}{2}, 1\right], \omega \in\left(\frac{1}{2}, 1\right],\left|\frac{\partial Y}{\partial r}\right|>\left|\frac{\partial Y}{\partial m}\right|$, and $\left|\frac{\partial F}{\partial m}\right|>\left|\frac{\partial F}{\partial r}\right|$ (i.e., each authority's tool has a first-order impact on its relatively dominant objective). These imply that $\frac{d r^{*}(m)}{d m}<0$ and $\frac{d m^{*}(r)}{d r}<0$ are monotonic (and they are continuous and unbounded, because the tools are unconstrained here). Hence, there can be only one crossing point of the reaction functions, i.e., one Nash Equilibrium.

Proof of Proposition 2. Consider the unconstrained socially optimal policy setting $(\widehat{r}, \widehat{m})$ and find the closest feasible values within $m \in \mathbb{Z}$ to $\widehat{m}$. Call these $m^{-}$(closest below) and $m^{+}$ (closest above). If

$$
\begin{aligned}
& {\left[\omega F\left(\varepsilon_{f}, \varepsilon_{y}, m^{+}, r^{*}\left(m^{+}\right)\right)^{2}+(1-\omega) Y\left(\varepsilon_{y}, \varepsilon_{f}, m^{+}, r^{*}\left(m^{+}\right)\right)^{2}\right.} \\
< & \left.\omega F\left(\varepsilon_{f}, \varepsilon_{y}, m^{-}, r^{*}\left(m^{+}\right)\right)^{2}+(1-\omega) Y\left(\varepsilon_{y}, \varepsilon_{f}, m^{-}, r^{*}\left(m^{+}\right)\right)^{2}\right] \\
& \wedge\left[\omega F\left(\varepsilon_{f}, \varepsilon_{y}, m^{-}, r^{*}\left(m^{-}\right)\right)^{2}+(1-\omega) Y\left(\varepsilon_{y}, \varepsilon_{f}, m^{-}, r^{*}\left(m^{-}\right)\right)^{2}\right. \\
< & \left.\omega F\left(\varepsilon_{f}, \varepsilon_{y}, m^{+}, r^{*}\left(m^{-}\right)\right)^{2}+(1-\omega) Y\left(\varepsilon_{y}, \varepsilon_{f}, m^{+}, r^{*}\left(m^{-}\right)\right)^{2}\right]
\end{aligned}
$$

then there will be multiple Nash Equilibria: given that REG plays $m^{+}$, the optimal response of MA is to set a $r^{*}$ such that $m^{+}$is optimal for REG; instead, given that REG plays $m^{-}$, the optimal response of MA is to set a $r^{*}$ such that $m^{-}$is optimal for REG.

Since $r^{*}(m)$ represents optimal play by MA for a given $m$, it is necessarily true that

$$
Y\left(\varepsilon_{y}, \varepsilon_{f}, m^{+}, r^{*}\left(m^{+}\right)\right)^{2}<Y\left(\varepsilon_{y}, \varepsilon_{f}, m^{-}, r^{*}\left(m^{+}\right)\right)^{2}
$$

and

$$
Y\left(\varepsilon_{y}, \varepsilon_{f}, m^{-}, r^{*}\left(m^{-}\right)\right)^{2}<Y\left(\varepsilon_{y}, \varepsilon_{f}, m^{+}, r^{*}\left(m^{-}\right)\right)^{2}
$$

Hence, the first condition in this proof can be rewritten to: there will be multiple Nash Equilibria when

$$
\begin{aligned}
{\left[F\left(\varepsilon_{f}, \varepsilon_{y}, m^{+}, r^{*}\left(m^{+}\right)\right)^{2}\right.} & \left.<F\left(\varepsilon_{f}, \varepsilon_{y}, m^{-}, r^{*}\left(m^{+}\right)\right)^{2}\right] \\
\wedge\left[F\left(\varepsilon_{f}, \varepsilon_{y}, m^{-}, r^{*}\left(m^{-}\right)\right)^{2}\right. & \left.<F\left(\varepsilon_{f}, \varepsilon_{y}, m^{+}, r^{*}\left(m^{-}\right)\right)^{2}\right]
\end{aligned}
$$

From $F\left(\varepsilon_{f}, \varepsilon_{y}, \widehat{m}, \widehat{r}\right)=0$ it follows that $F\left(\varepsilon_{f}, \varepsilon_{y}, \widehat{m}, r^{*}\left(m^{+}\right)\right)>0$, which (by $\frac{\partial F}{\partial m}<0$ from (4)) implies that REG will optimally set $m^{+}$when $r=r^{*}\left(m^{+}\right)$, i.e.,

$$
\left[F\left(\varepsilon_{f}, \varepsilon_{y}, m^{+}, r^{*}\left(m^{+}\right)\right)^{2}<F\left(\varepsilon_{f}, \varepsilon_{y}, m^{-}, r^{*}\left(m^{+}\right)\right)^{2}\right]
$$

and similarly $F\left(\varepsilon_{f}, \varepsilon_{y}, \widehat{m}, r^{*}\left(m^{-}\right)\right)<0$ implies that REG will set $m^{-}$when $r=r^{*}\left(m^{-}\right)$, i.e.,

$$
\left[F\left(\varepsilon_{f}, \varepsilon_{y}, m^{-}, r^{*}\left(m^{-}\right)\right)^{2}<F\left(\varepsilon_{f}, \varepsilon_{y}, m^{+}, r^{*}\left(m^{-}\right)\right)^{2}\right]
$$


Proof of Proposition 3. Consider the class of functional forms for which shocks are linearly separable

$$
\begin{aligned}
& Y\left(\varepsilon_{y}, \varepsilon_{f}, m, r\right)=\Theta_{y}\left(\varepsilon_{y}, \varepsilon_{f}\right)+\widetilde{Y}(m, r) \\
& F\left(\varepsilon_{y}, \varepsilon_{f}, m, r\right)=\Theta_{f}\left(\varepsilon_{y}, \varepsilon_{f}\right)+\widetilde{F}(m, r)
\end{aligned}
$$

and, therefore,

$$
\begin{aligned}
& Y^{2}=\Theta_{y}^{2}+\widetilde{Y}^{2}+2 \Theta_{y} \widetilde{Y} \\
& F^{2}=\Theta_{f}^{2}+\widetilde{F}^{2}+2 \Theta_{f} \widetilde{F}
\end{aligned}
$$

where we write $Y, F, \widetilde{Y}$ and $\widetilde{F}$ shorthand for $Y\left(\varepsilon_{y}, \varepsilon_{f}, m, r\right), F\left(\varepsilon_{y}, \varepsilon_{f}, m, r\right), \widetilde{Y}(m, r)$, and $\widetilde{F}(m, r)$, respectively.

By Proposition 1, $(\widehat{r}, \widehat{m})$ is the social optimum under unconstrained tools, at which $Y^{2}=$ $F^{2}=0$. As we are considering a symmetric constraint $m^{+}-\widehat{m}=\widehat{m}-m^{-}$, the key question is in which direction (above or below $\widehat{m}$ ) output and financial gaps increase faster. This is a question about the third derivatives of $Y^{2}$ and $F^{2}$. To see this, we take first, second and third derivatives of (11) and (12) to, respectively, $r$ and $m$ :

$$
\begin{aligned}
\frac{\partial Y^{2}}{\partial r} & =2 \frac{\partial \widetilde{Y}}{\partial r}\left(\Theta_{y}+\widetilde{Y}\right) \\
\frac{\partial^{2} Y^{2}}{\partial r^{2}} & =2 \frac{\partial^{2} \widetilde{Y}}{\partial r^{2}}\left(\Theta_{y}+\widetilde{Y}\right)+2\left(\frac{\partial \widetilde{Y}}{\partial r}\right)^{2} \\
\frac{\partial^{3} Y^{2}}{\partial r^{3}} & =2 \frac{\partial^{3} \widetilde{Y}}{\partial r^{3}}\left(\Theta_{y}+\widetilde{Y}\right)+6 \frac{\partial \widetilde{Y}}{\partial r} \frac{\partial^{2} \widetilde{Y}}{\partial r^{2}}
\end{aligned}
$$

and

$$
\begin{aligned}
\frac{\partial F^{2}}{\partial m} & =2 \frac{\partial \widetilde{F}}{\partial m}\left(\Theta_{y}+\widetilde{F}\right) \\
\frac{\partial^{2} F^{2}}{\partial m^{2}} & =2 \frac{\partial^{2} \widetilde{F}}{\partial m^{2}}\left(\Theta_{y}+\widetilde{F}\right)+2\left(\frac{\partial \widetilde{F}}{\partial m}\right)^{2} \\
\frac{\partial^{3} F^{2}}{\partial m^{3}} & =2 \frac{\partial^{3} \widetilde{F}}{\partial m^{3}}\left(\Theta_{y}+\widetilde{F}\right)+6 \frac{\partial \widetilde{F}}{\partial m} \frac{\partial^{2} \widetilde{F}}{\partial m^{2}}
\end{aligned}
$$

At the social optimum, $(\widehat{r}, \widehat{m})$, we have that $\left(\Theta_{y}+\widetilde{Y}\right)=0$ and $\left(\Theta_{y}+\widetilde{F}\right)=0$. Therefore, at the social optimum, $\frac{\partial Y^{2}}{\partial r}=0, \frac{\partial^{2} Y^{2}}{\partial r^{2}}>0, \frac{\partial F^{2}}{\partial m}=0$ and $\frac{\partial^{2} F^{2}}{\partial m^{2}}>0$. However, the third derivatives are of ambiguous sign. In other words, $Y^{2}$ and $F^{2}$ are always convex at the social optimum, and the issue at hand is whether that convexity is tilted in a particular direction. Figure 8 visualizes this in simplified (two-dimensional) form. 
Figure 8: Third derivatives and conflicting equilibria.

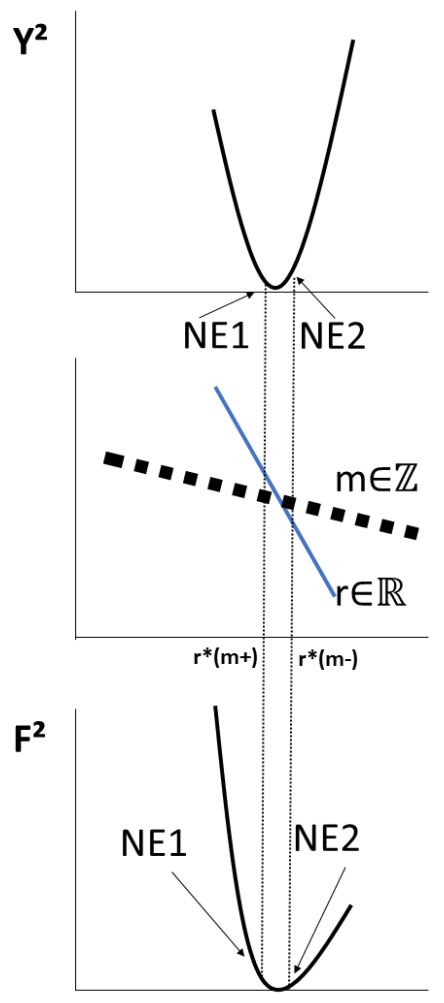

Let $\left(r^{*}\left(m^{-}\right), m^{-}\right)$be the first Nash Equilibrium $\left(Y_{1}, F_{1}\right)$ and $\left(r^{*}\left(m^{+}\right), m^{+}\right)$be the second $\left(Y_{2}, F_{2}\right)$. Then, by $\frac{d r^{*}(m)}{d m}<0$ (i.e., $m>\widehat{m} \Rightarrow r<\widehat{r}$ and vice versa),

$$
\begin{gathered}
\frac{\partial^{3} Y^{2}}{\partial r^{3}}>0 \wedge \frac{\partial^{3} F^{2}}{\partial m^{3}}>0 \Rightarrow Y_{1}^{2}>Y_{2}^{2} \wedge F_{1}^{2}<F_{2}^{2} \\
\frac{\partial^{3} Y^{2}}{\partial r^{3}}<0 \wedge \frac{\partial^{3} F^{2}}{\partial m^{3}}<0 \Rightarrow Y_{1}^{2}<Y_{2}^{2} \wedge F_{1}^{2}>F_{2}^{2}
\end{gathered}
$$

where both $Y_{1}^{2}>Y_{2}^{2} \wedge F_{1}^{2}<F_{2}^{2}$ and $Y_{1}^{2}<Y_{2}^{2} \wedge F_{1}^{2}>F_{2}^{2}$ imply conflict, given $\omega=1$ and $\lambda=1-v$ with $v \rightarrow 0^{+}$.

By (13) and (14), near the social optimum, where $\left(\Theta_{y}+\widetilde{Y}\right)=0$ and $\left(\Theta_{y}+\widetilde{F}\right)=0$, we can focus on

$$
\begin{aligned}
& \frac{\partial^{3} Y^{2}}{\partial r^{3}}=6 \frac{\partial \widetilde{Y}}{\partial r} \frac{\partial^{2} \widetilde{Y}}{\partial r^{2}} \\
& \frac{\partial^{3} F^{2}}{\partial m^{3}}=6 \frac{\partial \widetilde{F}}{\partial m} \frac{\partial^{2} \widetilde{F}}{\partial m^{2}}
\end{aligned}
$$


Here, $\frac{\partial \widetilde{Y}}{\partial r}<0$ and $\frac{\partial \widetilde{F}}{\partial m}<0$. Hence, $\frac{\partial^{2} \widetilde{Y}}{\partial r^{2}}>0$ and $\frac{\partial^{2} \widetilde{F}}{\partial m^{2}}>0$ imply (15), while $\frac{\partial^{2} \widetilde{Y}}{\partial r^{2}}<0$ and $\frac{\partial^{2} \widetilde{F}}{\partial m^{2}}<0$ imply (16).

Proof of Proposition 4. This is a graphical proof, based on Figures 4 and 5, as well as Figures 9 and 10. Figure 4 provides a correct representation in the following respects. First, by Proposition 3, preferences conflict near $\lambda=1$, which means that one Nash Equilibrium has a higher $F^{2}$ and the other a higher $Y^{2}$ (while at $\lambda=1, Y^{2}$ is always zero by (5)). Since, $\omega=1$ in the properties of Proposition 3 , the regulator's loss function is identical to $F^{2}$ in the respective equilibria. Moreover, for $\lambda$ arbitrarily close to 1 , MA certainly continues to prefer the equilibrium with the lower $Y^{2}$, whereas for $\lambda \rightarrow 0$ it would certainly prefer the other equilibrium. Hence, there exists a crossing point of the MA's loss functions under the respective equilibria, $\widehat{\lambda}$, which implies that one loss function is convex in $\lambda$ (for the equilibrium preferred at $\lambda$ near 1), while the other is concave. This implies two possibilities for the relation between $C$ and $\lambda$.

The first possibility is that $C$ in equation (9) is represented by the distance between the two MA lines (loss functions in the two equilibria), as in the right pane of Figure 4. The combination of a concave and a convex line with two crossing points (at $\lambda=1$ and $\lambda=\widehat{\lambda}$ ) then implies the hump-shape in Figure 5.

The second possibility is that $C$ in equation (9) is given by the distance between the two MA lines near $\lambda=1$ and $\lambda=\widehat{\lambda}$ (where the minimum distance must be between the MA's lines, because $C \rightarrow 0$ near $\lambda=1$ and $\lambda=\widehat{\lambda}$ ), but that at some intermediate values, $C$ is given by the distance between the two REG lines. This is the case represented in Figures 9 and 10 . Here the relationship between $C$ and $\lambda$ is that of a hump with a plateau rather than a peak.

Proof of Proposition 5. This is seen directly from Figures 6 and 7. Starting from $C=0$ at $\lambda=1$, a decrease of $\lambda$ always implies $C>0$ (Proposition 4), and therefore a rise in $E\left[F^{2}\right]$ from $\min \left\{F_{1}^{2}, F_{2}^{2}\right\}$ to $\frac{F_{1}^{2}+F_{2}^{2}}{2}$. Moreover, $\lambda^{\prime}$ can be either equal to $\widehat{\lambda}$ (as in Figure 6 ) or larger than $\widehat{\lambda}$ (as in Figure 7). 
Figure 9: Minimum coordination cost switches between authorities
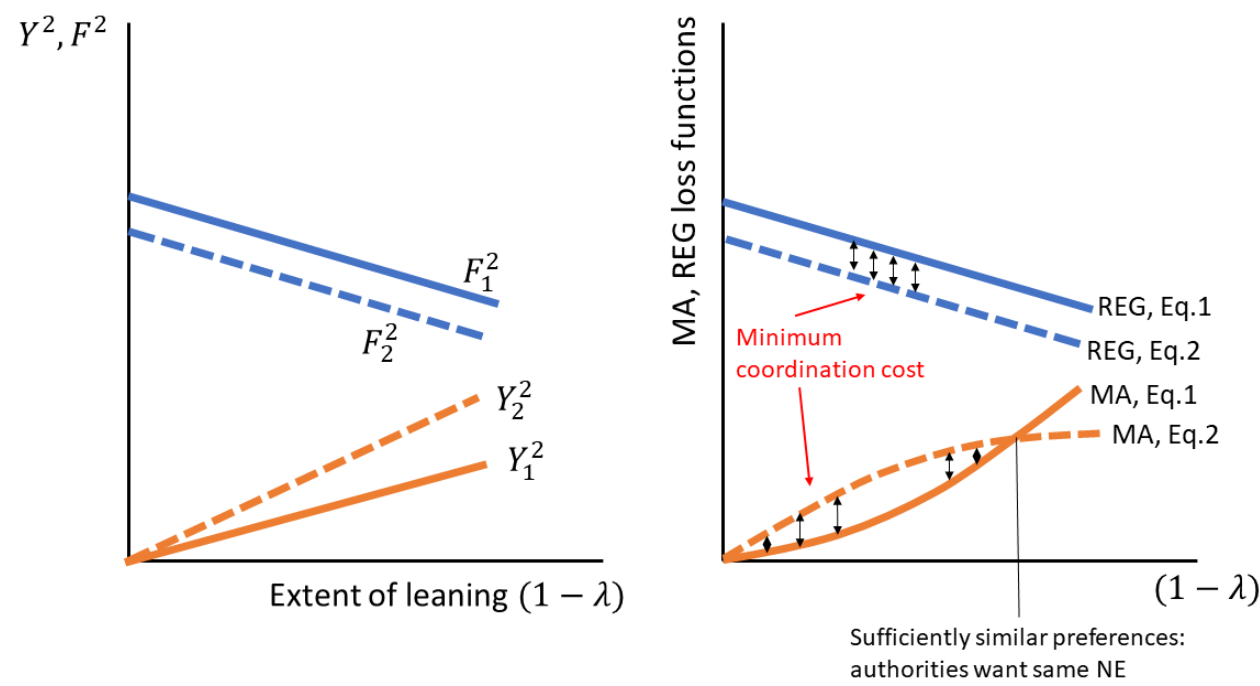

Figure 10: Hump-cum-plateau shaped relation

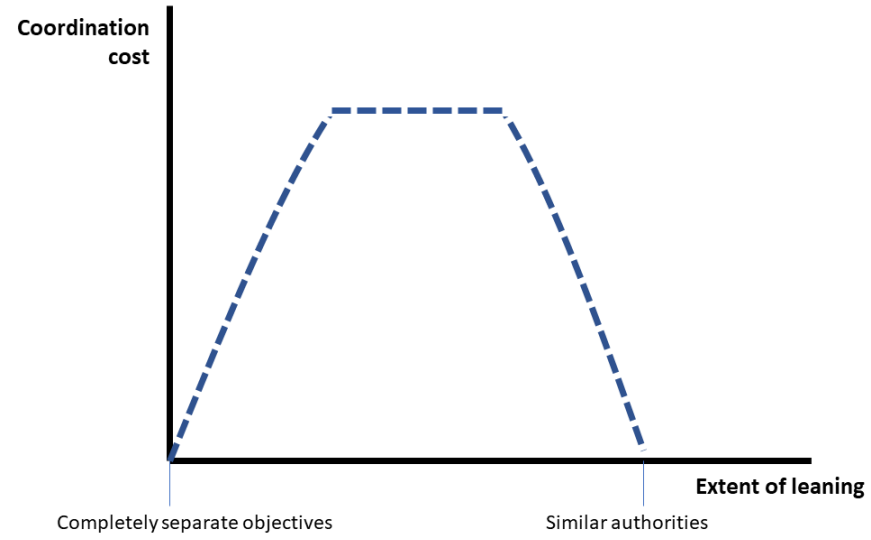




\section{APPENDiX B: ANAlytical EXAMPle USED to DERIVE FIGURES 1, 2 AND 3}

We use a linear functional form, to derive a quantifiable example for our charts.

$$
\begin{aligned}
& y=\varepsilon_{y}-\beta_{1} r-\beta_{2} m+\rho_{1} f \\
& f=\varepsilon_{f}-\gamma_{1} r-\gamma_{2} m+\rho_{2} y
\end{aligned}
$$

with $\beta_{1}, \beta_{2}, \gamma_{1}, \gamma_{2}>0$ and $\rho_{1}, \rho_{2} \in(0,1)$. This can be written to

$$
\begin{aligned}
Y & =\frac{\varepsilon_{y}+\rho_{1} \varepsilon_{f}-\left(\beta_{1}+\rho_{1} \gamma_{1}\right) r-\left(\beta_{2}+\rho_{1} \gamma_{2}\right) m}{\left(1-\rho_{1} \rho_{2}\right)} \\
F & =\frac{\varepsilon_{f}+\rho_{2} \varepsilon_{y}-\left(\gamma_{1}+\rho_{2} \beta_{1}\right) r-\left(\gamma_{2}+\rho_{2} \beta_{2}\right) m}{\left(1-\rho_{1} \rho_{2}\right)}
\end{aligned}
$$

When $r, m \in \mathbb{R}$, the reaction functions of the two authorities follow from the first-order conditions to their respective optimization problems, (5) and (6). That is, $r^{*}(m)$ and $m^{*}(r)$ follow from, respectively,

$$
\begin{aligned}
\frac{d}{d r}\left[\lambda Y^{2}+(1-\lambda) F^{2}\right] & =0 \\
\frac{d}{d m}\left[\omega F^{2}+(1-\omega) Y^{2}\right] & =0
\end{aligned}
$$

The analytical solutions for $r^{*}(m)$ and $m^{*}(r)$ are rather long expressions, but the expression for the Nash Equilibrium is extremely simple. ${ }^{6}$ The Nash Equilibrium is found be replacing $m^{*}(r)$ into $r^{*}(m)$ (or vice versa) and solving. In this case, there is a unique solution, which is

$$
\begin{aligned}
r^{N E} & =\frac{\beta_{2} \varepsilon_{f}-\gamma_{2} \varepsilon_{y}}{\beta_{2} \gamma_{1}-\beta_{1} \gamma_{2}} \\
m^{N E} & =\frac{\beta_{1} \varepsilon_{f}-\gamma_{1} \varepsilon_{y}}{\beta_{1} \gamma_{2}-\beta_{2} \gamma_{1}}
\end{aligned}
$$

Implementing these in (21) and (22) gives $Y=0$ and $F=0$, and therefore the Nash Equilibrium is socially optimal: $\left(r^{N E}, m^{N E}\right)=(\widehat{r}, \widehat{m})$.

We now consider a constrained macroprudential tool. In this example, we will consider that there are only two settings for $m$, namely tight $(m=1)$ and neutral $(m=0)$. The MA's

\footnotetext{
${ }^{6}$ Both the full expressions for the reactions functions, and the derivation of the Nash Equilibrium are contained in a Mathematica file that is available from the author upon request.
} 
optimization is unchanged compared to (23). REG's problem can now be written as

$$
\begin{aligned}
m^{*}= & 1 \Leftrightarrow \omega\left(\frac{\varepsilon f+\rho_{2} \varepsilon_{y}-\left(\gamma_{1}+\rho_{2} \beta_{1}\right) r-\left(\gamma_{2}+\rho_{2} \beta_{2}\right)}{\left(1-\rho_{1} \rho_{2}\right)}\right)^{2} \\
& +(1-\omega)\left(\frac{\varepsilon_{y}+\rho_{1} \varepsilon_{f}-\left(\beta_{1}+\rho_{1} \gamma_{1}\right) r-\left(\beta_{2}+\rho_{1} \gamma_{2}\right)}{\left(1-\rho_{1} \rho_{2}\right)}\right)^{2} \\
> & \omega\left(\frac{\varepsilon_{f}+\rho_{2} \varepsilon_{y}-\left(\gamma_{1}+\rho_{2} \beta_{1}\right) r}{\left(1-\rho_{1} \rho_{2}\right)}\right)^{2} \\
& +(1-\omega)\left(\frac{\varepsilon_{y}+\rho_{1} \varepsilon_{f}-\left(\beta_{1}+\rho_{1} \gamma_{1}\right) r}{\left(1-\rho_{1} \rho_{2}\right)}\right)^{2}
\end{aligned}
$$

That is, it is a comparison of the value of (6) for $m=1$ and $m=0$. The solution takes the form

$$
m^{*}=1 \Leftrightarrow r<\bar{r}
$$

There is a value, $\bar{r}$, given by parameters, which acts as a threshold. If the interest rate is below this threshold then REG sets tight policy, and if the interest rate is above this threshold, then it sets loose policy.

For this example, we use the following parameter values: $\lambda=1, \omega=0.75, \varepsilon_{y}=-5, \varepsilon_{f}=0$, $\beta_{1}=2, \beta_{2}=0.5, \gamma_{1}=0.5, \gamma_{2}=2, \rho_{1}=0.5, \rho_{2}=0.5$.

With unconstrained tools, Figures 1 and 2 highlight the emergence of a single, socially optimal Nash Equilibrium. We can calculate this Nash Equilibrium using (25) and (26) as $\left(r^{N E}, m^{N E}\right)=$ $(-2.67,0.67)$ (and hence, in the notation used in the general form, we indeed have $m^{+}=1$ and $\left.m^{-}=0\right)$.

With constrained macroprudential policy, the above parameterization gives the following for (28):

$$
m^{*}=1 \Leftrightarrow r<-2.45
$$

That is, if $r<-2.45$ it is optimal for REG to set $m=1$, while for $r>-2.45$ it is optimal to set $m=0$ (and $r=-2.45$ is a knife-edge where REG is indifferent). This is shown in Figure 3.

Moreover, from (23) we now get that

$$
r^{*}=-2.89 \text { if } m=1 ; r^{*}=-2.22 \text { if } m=0
$$

Taken together, these imply the existence of two Nash Equilibria, namely at

$$
\left(r^{N E}, m^{N E}\right)=\left\{\begin{array}{l}
(-2.89,1) \\
(-2.22,0)
\end{array}\right.
$$

The reason is that given tight macroprudential policy, the optimal interest rate $\left(r^{*}=-2.89\right)$ is below the constraint $(r<-2.45)$ for which $m^{*}=1$ and the tight policy is optimal for 
REG. But given loose policy by REG, the optimal interest rate $\left(r^{*}=-2.22\right)$ is above the constraint $(r>-2.45)$ for which $m^{*}=0$ and thus the loose policy is optimal for REG. Both combinations (tight macroprudential policy with a lower policy rate; loose macroprudential policy with a higher policy rate) are sustainable as Nash Equilibria. 


\section{REFERENCES}

Acharya, Viral V., and Hassan Naqvi, 2012, The seeds of a crisis: A theory of bank liquidity and risk-taking over the business cycle, Journal of Financial Economics 106(2), 349366.

Adrian, Tobias, and Nellie Liang, 2018, Monetary policy, financial conditions, and financial stability, International Journal of Central Banking 14(1), 73-131.

Agur, Itai, and Maria Demertzis, 2013, "Leaning against the wind" and the timing of monetary policy, Journal of International Money and Finance 35, 179-194.

Agur, Itai, and Sunil Sharma, 2014, Rules, discretion, and macro-prudential policy, in: Institutional Structure of Financial Regulation: Theories and International Experiences, Robin Hui Huang and Dirk Schoenmaker (eds.), Routledge.

Agur, Itai and Maria Demertzis, 2018, Will macroprudential policy counteract monetary policy's effects on financial stability, Bruegel Working Paper 2018/1.

Allen, Franklin, Elena Carletti and Douglas Gale, 2014, Money, financial stability and efficiency, Journal of Economic Theory 149, 100-127.

Angelini, Paolo, Stefano Neri, and Fabio Panetta, 2012, Monetary and macroprudential policies, ECB Working Paper 1449.

Blanchard, Olivier, and Jordi Galí, 2007, Real wage rigidities and the new keynesian model, Journal of Money, Credit and Banking 39(1), 35-65.

Blake, Andrew P., and Tatiana Kirsanova, 2012, Discretionary policy and multiple equilibria in LQ RE models, Review of Economic Studies 79, 1309-1339.

Bodenstein, Martin, Luca Guerrieri and Joe LaBriola, 2016, Macroeconomic policy games, mimeo.

Borio, Claudio, and William White, 2004, Whither monetary policy and financial stability? The implications of evolving policy regimes, BIS Working Paper No. 147.

Borio, Claudio, 2014, The financial cycle and macroeconomics: what have we learnt, Journal of Banking and Finance 45, 182-198.

Brunnermeier, Markus K., and Yann Koby, 2017, The "reversal interest rate": an effective lower bound on monetary policy, mimeo, Princeton University.

Carrillo, Julio A., Enrique G. Mendoza, Victoria Nuguer, Jessica Roldán-Peña, 2017, Tight money tight credit: coordination failure in the conduct of monetary and financial policies, NBER Working Paper 23151.

Cavallino, Paolo, and Damiano Sandri, 2018, The expansionary lower bound: Contractionary monetary easing and the trilemma, IMF Working Paper, forthcoming. 
Cecchetti, Stephen G., and Marion Kohler, 2014, When capital adequacy and interest rate policy are substitutes (and when they are not), International Journal of Central Banking 10(3), 205-231.

Collard, Fabrice, Harris Dellas, Behzad Diba, and Olivier Loisel, 2017, Optimal monetary and prudential policies, American Economic Journal: Macroeconomics 9(1), 40-87.

De Paoli, Bianca, and Matthias Paustian, 2017, Coordinating monetary and macroprudential policies, Journal of Money, Credit and Banking 49 (2-3), 319-349.

Dell'Ariccia, Giovanni, and Robert Marquez, 2006, Lending booms and lending standards, Journal of Finance 61(5), 2511-2546.

Dell'Ariccia, Giovanni, Luc Laeven, and Robert Marquez, 2014, Real interest rates, leverage, and bank risk-taking, Journal of Economic Theory 149, 65-99.

Dell'Ariccia, Giovanni, Luc Laeven, and Gustavo Suarez, 2017, Bank leverage and monetary policy's risk-taking channel: Evidence from the United States, Journal of Finance 72(2), 613-654.

Diamond, Douglas W., and Raghuram G. Rajan, 2012, Illiquid banks, financial stability, and interest rate policy, Journal of Political Economy 120(3), 552-591.

Disyatat, Piti, 2010, Inflation targeting, asset prices and financial imbalances: contextualizing the debate, Journal of Financial Stability 6(3), 145-155.

Drees, Burkhard, Bernhard Eckwert and Felix Várdy, 2013, Cheap money and risk taking: opacity versus underlying risk, European Economic Review 62(1), 114-129.

Dubecq, Simon, Benoit Mojon and Xavier Ragot, 2015, Fuzzy capital requirements, riskshifting and the risk-taking channel of monetary policy, International Journal of Central Banking 11(1), 71-101.

Eggertsson, Gauti B., Ragnar E. Juelsrud, and Ella Getz Wold, 2017, Are negative nominal rates expansionary? NBER Working Paper No. 24039.

Eijffinger, Sylvester C.W., 2001, The conduct of monetary policy and an evaluation of the economic situation in Europe, Briefing Paper for the European Parliament, May 2001.

Farhi, Emmanuel, and Jean Tirole, 2012, Collective moral hazard, maturity mismatch and systemic bailouts, American Economic Review 102(1), 60-93.

Filardo, Andrew, and Phurichai Rungcharoenkitkul, 2016, A quantitative case for leaning against the wind, BIS Working Paper No. 594.

Freixas, Xavier, Antoine Martin, and David Skeie, 2011, Bank liquidity, interbank markets, and monetary policy, Review of Financial Studies 24(8), 2656-2692. 
Galati, Gabriele, and Richhild Moessner, 2013, Macroprudential policy - a literature review, Journal of Economic Surveys 27(5), 846-878.

Galí, Jordi, 2014, Monetary policy and rational asset price bubbles, American Economic Review 104(3), 721-752.

Gerdrup, Karsten R., Frank Hansen, Tord Krogh, and Junior Maih, 2017, Leaning against the wind when credit bites back, International Journal of Central Banking 13(3), 287320.

Gertler, Mark, Nobuhiro Kiyotaki, and Andrea Prestipino, 2017, A macroeconomic model with financial panics, NBER Working Paper No. 24126.

Goodhart, Charles A. E., 2000, The organisational structure of banking supervision, FSI Occasional Papers No. 1 - November 2000-10-25.

Heider, Florian, Farzad Saidi, and Glenn Schepens, 2017, Life below zero: Bank lending under negative policy rates, mimeo.

Hong, Gee Hee, and John Kandrac, 2018, Pushed past the limit? How Japanese banks reacted to negative rates. IMF Working Paper (forthcoming).

Jiménez, Gabriel, Steven Ongena, José-Luis Peydró and Jesús Saurina, 2014, Hazardous times for monetary policy: what do twenty-three million bank loans say about the effects of monetary policy on credit risk-taking? Econometrica, 82(2), 463-505.

Kim, Soyoung, and Aaron Mehrotra, 2018, Effects of monetary and macroprudential policies - evidence from inflation targeting economies, Journal of Money, Credit and Banking 50(5), 967-992.

Laureys, Lien, and Roland Meeks, 2018, Monetary and macroprudential policies under rules and discretion, Economics Letters 170, 104-108.

Lim, Cheng Hoon, Alejo Costa, Torsten Wezel, Akira Otani, Francesco Columba, Mustafa Sayid, Xiaoyong Wu, and Piyabha Kongsamut, 2011, Macroprudential policy: what instruments and how to use them? lessons from country experiences, IMF Working Paper No. 11/238.

Loisel, Olivier, Aude Pommeret and Franck Portier, 2012, Monetary policy and herd behavior: leaning against bubbles, Banque de France Working Paper No. 412.

Loisel, Olivier, 2014, Discussion of "Monetary and macroprudential policies in an estimated DSGE model of the Euro Area", International Journal of Central Banking 10(2), 237247.

Maddaloni, Angela and José-Luis Peydró, 2011, Bank risk-taking, securitization, supervision, and low interest-rates: Evidence from the Euro Area and US lending standards, Review of Financial Studies 24, 2121-65. 
Morris, Stephen and Hyun Song Shin, 2002, Social value of public information, American Economic Review 92(5), 1521-34

Morris, Stephen, and Hyun Song Shin, 2016, Risk premium shifts and monetary policy: A coordination approach, in: Monetary policy through asset markets: Lessons from unconventional measures and implications for an integrated world, eds. Elías Albagli, Diego Saravia, and Michael Woodford, Central Bank of Chile.

Nier, Erlend W., Jacek Osiński, Luis I. Jácome, and Pamela Madrid, 2011, Towards effective macroprudential policy frameworks: an assessment of stylized institutional models, IMF WP 11/250

Perotti, Enrico, Lev Ratnovski and Razvan Vlahu, 2011, Capital regulation and tail risk, International Journal of Central Banking 7(4), 123-163.

Rajan, Raghuram G., 2006, Has finance made the world riskier? European Financial Management, 12(4), 499-533.

Richter, Björn, Moritz Schularick, and Ilhyock Shim, 2018, The macroeconomic effects of macroprudential policy, BIS Working Paper No. 740.

Schularick, Moritz, and Alan M. Taylor, 2012, Credit booms gone bust: Monetary policy, leverage cycles, and financial crises, 1870-2008, American Economic Review, 102(2), 1029-61.

Stein, Jeremy C., 2014, Incorporating financial stability considerations into a monetary policy framework, Speech at the Federal Reserve Board, March 21, 2014.

Svensson, Lars E.O., 2014, Inflation targeting and "leaning against the wind", International Journal of Central Banking 10(2), 103-114.

Svensson, Lars E.O., 2017a, Cost-benefit analysis of leaning against the wind. Journal of Monetary Economics 90, 193-213.

Svensson, Lars E.O., 2017b, Leaning against the wind: costs and benefits, effects on debt, leaning in DSGE models, and a framework for comparison of results, International Journal of Central Banking 13(3), 385-408.

Valencia, Fabian, 2014, Monetary policy, bank leverage, and financial stability, Journal of Economic Dynamics \& Control 47, 20-38.

Van der Ghote, Alejandro, 2018, Coordinating monetary and financial regulatory policies, ECB Working Paper No. 2155. 